\title{
Influence of Inorganic Solution Components on Lithium Carbonate Crystal Growth
}

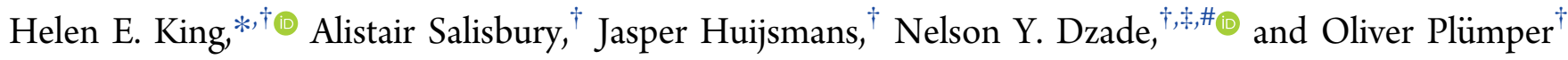 \\ ${ }^{\dagger}$ Department of Earth Sciences, Utrecht University, Princetonlaan 8a, 3584 CB Utrecht, The Netherlands \\ ${ }^{\star}$ School of Chemistry, Cardiff University, Main Building, Park Place, CF10 3AT, Cardiff, United Kingdom
}

Supporting Information

\begin{abstract}
Lithium-bearing brines are an increasingly attractive source of $\mathrm{Li}$ for extraction. One extraction mechanism is the removal of $\mathrm{Li}$ from the fluid phase through the precipitation of zabuyelite $\left(\mathrm{Li}_{2} \mathrm{CO}_{3}\right)$. The chemistry of the brine plays an important role in this process because ions in solution can compete for the components of the Li-carbonate phase. Here we explore the effect of different brine components on the precipitation of zabuyelite using experiments and computational simulations. Crystals formed in all solutions showed morphological evidence for potential transformation from a precursor phase. Our study indicates that $\mathrm{Ca}^{2+}$ and $\mathrm{SO}_{4}^{2-}$ are incorporated into the precipitated

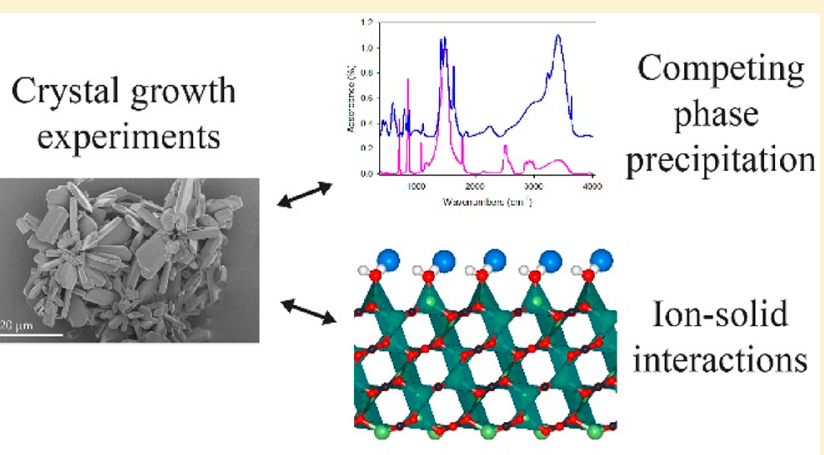
zabuyelite crystals. Sulfate also interacts directly with specific surfaces on the growing crystal and is expected to form ion pairs with $\mathrm{Li}^{+}$in solution. Similarly, $\mathrm{Na}^{+}$appears to form ion pairs in solution with the carbonate ion, slowing nucleation of zabuyelite in the experiments. $\mathrm{K}^{+}$and $\mathrm{Cl}^{-}$may interact with the growing zabuyelite crystals but do not appear to affect zabuyelite nucleation and growth times. These experiments highlight the importance of understanding the solution chemistry on zabuyelite formation in order to predict the efficiency of extraction processes and the purity of the solids.
\end{abstract}

\section{INTRODUCTION}

Lithium is a well-known commodity due to its use in the pharmaceutical industry; ${ }^{1}$ however, its value has soared in recent years due to its use in rechargeable batteries. This increase in demand has resulted in a sharp rise in global consumption rate from $200 \mathrm{t}$ per year in 1994 to over 40000 in 2008. ${ }^{2,3}$ At present the majority of $\mathrm{Li}$ is extracted from pegmatite rocks, which contain the Li-feldspar spodumene $\left(\mathrm{LiAl}\left(\mathrm{SiO}_{3}\right)_{2}\right)$ and the Li-mica lepidolite $\left(\mathrm{KLi}_{2} \mathrm{AlSi}_{4} \mathrm{O}_{10} \mathrm{~F}_{2}\right)$. However, $66 \%$ of the world's total $\mathrm{Li}$ is present in brines; thus, these sources have the highest capacity for long-term $\mathrm{Li}$ extraction. $^{4}$ Brines also have the additional benefit that extraction of $\mathrm{Li}$ is proposed to be between 30 and $50 \%$ less expensive than from mined mineral ores. ${ }^{5} \mathrm{Li}$ can be extracted from brines via adsorption to inorganic solids, such as manganese $^{6}$ and titanium oxides, ${ }^{7}$ and using membrane electrolysis. ${ }^{8}$ Alternatively, brines can be evaporated to precipitate $\mathrm{Li}$ directly from solution, typically as the $\mathrm{Li}$ carbonate phase zabuyelite $\left(\mathrm{Li}_{2} \mathrm{CO}_{3}\right) .{ }^{9} \mathrm{Li}$ extraction in the formation of zabuyelite has also been suggested as part of recycling procedures at the other end of the battery life cycle. ${ }^{10}$ The exact extraction method chosen for $\mathrm{Li}_{2} \mathrm{CO}_{3}$ production depends on the composition of the aqueous solution, where the $\mathrm{Mg}^{2+}$ content is the limiting factor in brines as this ion interferes with many of the extraction techniques currently used. $^{8}$
Despite its importance as a product in many different primary and secondary $\mathrm{Li}$ resources, there are only a limited number of studies on zabuyelite formation from solution. Typically, these reflect the nucleation and growth of $\mathrm{Li}_{2} \mathrm{CO}_{3}$ phases in the presence of organic molecules ${ }^{11}$ and do not consider the effect of inorganic ions in brine on Li-carbonate formation. Brines of interest for Li extraction have a varied and complex solution chemistry with high concentrations of $\mathrm{Na}^{+}$, $\mathrm{K}^{+}, \mathrm{Cl}^{-}, \mathrm{SO}_{4}{ }^{2-}$, as well as $\mathrm{Ca}^{2+}$ and $\mathrm{Mg}^{2+}$ concentrations up to 4 wt \%. ${ }^{12}$ The formation of ion pairs between the constituents of other oxyanion-bearing mineral phases, such as magnesite $\left(\mathrm{MgCO}_{3}\right)$ and sulfate hemihydrate, has been shown to significantly change the ability of the mineral to form from aqueous solution. ${ }^{13,14}$ In addition, dissolved ions can form direct interactions with different surfaces on a growing crystal, influencing the stability of the surface and thus its ability to grow. For example, the presence of $\mathrm{Li}^{+}$in solution is known to bind to the $\{0001\}$ surfaces of calcite $\left(\mathrm{CaCO}_{3}\right)$ crystals, stabilizing this face ${ }^{15}$ and changing the final crystal morphology. ${ }^{16,17}$ In contrast, the presence of different background ions, i.e., those that do not interact directly with the mineral constituents in solution or at the mineral surface,

Received: June 18, 2019

Revised: September 8, 2019

Published: November 4, 2019 
Table 1. List of Crystal Growth Experiments Conducted ${ }^{a}$

\begin{tabular}{|c|c|c|c|c|c|c|}
\hline \multirow[b]{2}{*}{ additive } & \multirow[b]{2}{*}{ concentration (M) } & \multicolumn{2}{|c|}{$\mathrm{pH}$} & \multirow[b]{2}{*}{ ionic strength (M) } & \multicolumn{2}{|c|}{ saturation index } \\
\hline & & $\mathrm{LiBr}+$ additive & experiment & & calcite & hydromagnesite \\
\hline none & & 9.13 & 11.78 & 1.5 & & \\
\hline \multirow[t]{2}{*}{$\mathrm{NaCl}$} & 0.1 & 8.82 & 11.62 & 1.6 & & \\
\hline & 1.0 & 8.95 & 11.77 & 2.5 & & \\
\hline \multirow[t]{2}{*}{$\mathrm{KCl}$} & 0.1 & 8.57 & 11.72 & 1.6 & & \\
\hline & 1.0 & 8.71 & 11.76 & 2.5 & & \\
\hline \multirow{2}{*}{$\mathrm{CaCl}_{2}$} & 0.033 & 7.95 & n.d. ${ }^{b}$ & 1.6 & 3.68 & \\
\hline & 0.33 & 7.98 & n.d. ${ }^{b}$ & 2.5 & 4.52 & \\
\hline \multirow[t]{2}{*}{$\mathrm{MgCl}_{2}$} & 0.033 & 10.05 & n.d. ${ }^{b}$ & 1.6 & & 16.87 \\
\hline & 0.33 & 9.08 & n.d. ${ }^{b}$ & 2.5 & & 20.88 \\
\hline \multirow[t]{2}{*}{$\mathrm{Na}_{2} \mathrm{SO}_{4}$} & 0.033 & 8.54 & 11.72 & 1.6 & & \\
\hline & 0.33 & 8.39 & 11.76 & 2.5 & & \\
\hline
\end{tabular}

${ }^{a}$ Measurements of $\mathrm{pH}$ were conducted at room temperature, where the nucleation of the Li-carbonate phase was inhibited. Saturation index calculation obtained from PHREEQC simulations of the initial solution at $90^{\circ} \mathrm{C}$ when $\mathrm{Ca}$ or $\mathrm{Mg}$ were present in the initial solution. ${ }^{b}$. $\mathrm{d}_{\text {. }}=\mathrm{not}$ determined due to immediate precipitate formation.

has been proposed to enhance or inhibit ion and surface dehydration, ${ }^{18,19}$ altering precipitation rates. Therefore, the solution components may contribute either positively or negatively to the formation of Li-carbonate from aqueous solutions.

This study examines the effect of typical brine components on the precipitation of zabuyelite. Precipitates were formed by mixing carbonate-bearing and Li-bearing solutions ${ }^{20}$ with and without inorganic ions observed in the mineral type locality brine from Lake Zabuye. ${ }^{21}$ Interactions between different ions in solution were examined in situ using Raman spectroscopy and compared with predictions from thermodynamic solution speciation calculations. In contrast, direct interaction between different ions in solution and the solid zabuyelite phase were examined in situ using attenuated total reflectance infrared spectroscopy. Potential changes in crystal morphology due to ion-solid interactions observed in electron microscopy images were verified using atomistic simulations. The experiments and simulations demonstrate that $\mathrm{K}^{+}$and $\mathrm{Na}^{+}$have minimal direct influence on the growth of zabuyelite. However, $\mathrm{Ca}^{2+}$ and $\mathrm{Mg}^{2+}$ outcompete $\mathrm{Li}^{+}$for carbonate-phase growth, whereas there is evidence that sulfate directly interacts with the zabuyelite crystals during growth.

\section{MATERIALS AND METHODS}

2.1. Crystal Formation. The procedure described by Taborga et $\mathrm{al}^{20}$ was used to precipitate the Li-carbonate phase, with the exception that $\mathrm{LiBr}$ was used instead of $\mathrm{LiCl}$ so that we could examined the effects of $\mathrm{Cl}^{-}$ions on the synthesis. Experiments were conducted using a multiplate stirrer (IKA RT 15) allowing four solutions to be tested in duplicate for each experimental set. New reactant solutions were produced for each set of experiments. A water bath was heated to $80^{\circ} \mathrm{C}$ prior to each experiment, and aluminum foil was used as a lid to maintain the temperature and water levels during the experiment. Twenty milliliters of a $0.5 \mathrm{M} \mathrm{LiBr}$ solution with or without additional salts $\left(\mathrm{NaCl}, \mathrm{KCl}, \mathrm{MgCl}_{2}, \mathrm{CaCl}_{2}, \mathrm{Na}_{2} \mathrm{SO}_{4}\right)$ at ionic strengths of 1 or $0.1 \mathrm{M}$ was added to $150 \mathrm{~mL}$ glass bottles sitting in the water bath. Each bottle contained a magnetic stirrer and was sealed with a rubber septum. The Li-bearing solution was stirred at $300 \mathrm{rpm}$ for $20 \mathrm{~min}$ to allow it to reach the temperature of the water bath prior to addition of the carbonate-bearing solution. Twenty milliliters of the carbonate-bearing solution $\left(0.5 \mathrm{M} \mathrm{Na}_{2} \mathrm{CO}_{3}, \mathrm{pH}\right.$ : 12.04) was then slowly added to the $\mathrm{Li}$ solution at a rate of $3 \mathrm{~mL} / \mathrm{min}$ using a syringe pump. A list of the experiments conducted and the $\mathrm{pH}$ of the solutions measured at room temperature can be found in Table 1. The solution was continuously stirred for another hour before the precipitate was extracted from the solution using gravity filtration. In preparation for analysis of the crystal morphology and phase identification, the precipitate was dried in a desiccator for at least $24 \mathrm{~h}$. Phase identification of the bulk samples was conducted using a Bruker D8 Advance X-ray diffractometer equipped with a $\mathrm{Cu}$ source.

2.2. Vibrational Spectroscopy. Competing ion complexations in solution and water structure were assessed using a polytetrafluoroethylene lined, temperature-controlled fluid cell built at the University of Münster, Germany. ${ }^{22}$ Solutions (0.1, 1, and $2 \mathrm{M} \mathrm{Na}_{2} \mathrm{CO}_{3}, 2 \mathrm{M}$ $\mathrm{Na}_{2} \mathrm{SO}_{4}$, and water equilibrated with Li-carbonate at room temperature including dilutions by $2 / 3$ and $1 / 2$ ) were heated to temperatures between 30 and $80{ }^{\circ} \mathrm{C}$ and measured using the 488 $\mathrm{nm}$ laser of a WITec 300 alpha Raman spectrometer. A 50× long working distance objective lens was used to focus below the sapphire window at the top of the cell. A grating of 600 grooves $/ \mathrm{mm}$ was first used to obtain the complete spectral range of interest (100-4000 $\mathrm{cm}^{-1}$ ) for each temperature and solution. The most intense Raman band for the ions, which are known to be affected by the formation of ions pairs in solution, ${ }^{23,24}$ were then obtained at a higher spectral resolution using a 2400 grooves/mm grating. Each spectrum was acquired for 5-60 s 10 times and integrated to increase the signal-tonoise ratio. Individual crystals from the precipitation experiments were also tested using the same Raman spectrometer. However, to reduce fluorescence of the solid samples, a Nd:YAG laser at $532 \mathrm{~nm}$ was used for the analysis of the precipitates with a grating of 600 grooves $/ \mathrm{mm}$. Each spectrum of the solids was acquired for $1 \mathrm{~s}, 15$ times and integrated. Data reduction including the removal of spectral background and spurious detector noise was conducted using the WITec Project 4.0 program. The Raman bands were fitted using Voigt functions in the Fityk program. ${ }^{25}$

Diffuse reflectance infrared Fourier transform spectroscopy (DRIFTS) was also used to test for any changes in bulk chemistry of the precipitates related to the incorporation of significant concentrations of additional ions from solution. DRIFTS analysis was carried out using a Thermo Fisher Scientific Nicolet 6700 infrared spectrometer. For the analysis, subsamples of precipitates from each experiment were mixed with IR transparent $\mathrm{KBr}$ powder. Each spectrum was acquired using 64 scans with a spectral resolution of 4 $\mathrm{cm}^{-1}$. Surface complexation of solution species onto the surface of $\mathrm{Li}$ carbonate was tested in situ using attenuated total reflectance infrared spectroscopy (ATR-IR). The ATR-IR measurements were performed using a Thermo Fisher Scientific Nicolet iS5 apparatus with iD7 diamond crystal ATR accessory. ATR-IR experiments were performed on solid $\mathrm{Li}$-carbonate grown in solutions with only $\mathrm{LiBr}$ and $\mathrm{NaCO}_{3}$ exposed to $1 \mathrm{M} \mathrm{NaCl}, 1 \mathrm{M} \mathrm{KCl}, 0.33 \mathrm{M} \mathrm{MgCl}_{2}$, and $0.25 \mathrm{M} \mathrm{Na}_{2} \mathrm{SO}_{4}$ solutions. In addition, Li-carbonate precipitated in the presence of $\mathrm{K}^{+}$, $\mathrm{Na}^{+}$, and $\mathrm{SO}_{4}{ }^{2-}$ was also tested in $1 \mathrm{M} \mathrm{KCl}, 1 \mathrm{M} \mathrm{NaCl}$, and $0.33 \mathrm{M}$ $\mathrm{Na}_{2} \mathrm{SO}_{4}$ solutions respectively to examine the effect of changes in specific surfaces on the adsorption spectra. 
2.3. Precipitate Imaging. Precipitates from different experiments were attached to carbon stickers and coated with $6 \mathrm{~nm}$ of platinum before being examined using a FEI Helios Nanolab G3 scanning electron microscope (SEM) equipped with a focused ion beam. Chemical analysis of the precipitates was conducted during the SEM analysis using energy dispersive X-ray spectroscopy (EDX). Lithium cannot be analyzed using conventional EDX detectors; therefore, the presence of $\mathrm{C}$ and $\mathrm{O}$, but absence of a cation, was used to identify the Li-carbonate phase. Crystal aspect analysis was conducted based on the system described by Um et al. ${ }^{26}$ for ice crystals, which show a morphology similar to the crystals formed in the synthesis experiments. Analysis of crystal morphology aspect parameters: total length, total width, height from central face to top of crystal, width of central face, and width of side faces, was conducted in Adobe Photoshop. Crystals used in the aspect analysis were chosen that were lying with the longest crystal axis parallel to the electron beam to limit measurement errors due to image perspective effects. In addition, only crystals where the entire length of the crystal could be seen were chosen. These requirements limited the number of crystals that were measurable, and thus aspect ratios for 10 crystals from each experiment without and with the highest concentration of additional ions were obtained.

2.4. Computational Methods. Solution ion activities and saturation states with respect to different solid phases were modeled using the PHREEQC geochemical program from the USGS. ${ }^{27}$ The solutions were modeled using the Lawrence Livermore National Library (llnl) database. None of the databases available with PHREEQC contain thermodynamic parameters for the $\mathrm{Li}_{2} \mathrm{CO}_{3}$ phase zabuyelite and had minimum interaction coefficients for $\mathrm{Li}$ ion pairs. Therefore, these simulations are used mainly to evaluate the supersaturation of the system with respect to secondary mineral precipitates including $\mathrm{Mg}$-, $\mathrm{Ca}-, \mathrm{K}$ - and $\mathrm{Na}$-carbonate phases and $\mathrm{Na}$ carbonate ion pairs.

All atomistic simulations of the adsorption of $\mathrm{Na}^{+}, \mathrm{K}^{+}, \mathrm{Mg}^{2+}, \mathrm{Cl}^{-}$, and $\mathrm{SO}_{4}{ }^{2-}$ on the surfaces of zabuyelite were executed within the framework of the dispersion-corrected density functional theory (DFT-D3) method, as implemented in the Vienna ab initio Simulation Package (VASP). The VASP code calculates the lowestenergy configuration (ground state) of a material by structural energy minimization through atom reassembly, movement, and rotation. The lowest-energy configuration is satisfied when the residual HellmanFeynman force on the relaxed atom reaches $0.01 \mathrm{eV} / \AA$. . Additionally, to obtain an accuracy of the interiterative energy change of $10^{-6} \mathrm{eV}$, the kinetic energy cutoff for the plane-wave basis was set to $600 \mathrm{eV}$. The initial zabuyelite cell parameters were taken from the work of Idemoto et al. ${ }^{28}$ A Monkhorst-Pack K-point mesh of $3 \times 5 \times 4$ and 3 $\times 5 \times 1$ has been used to describe the Brillouin zone of the bulk and surface calculations, respectively. The Monkhorst-Pack scheme ensures homogeneous distribution of the sampling K-points within the Brillouin zone, and the columns and rows of the K-points are parallel to the reciprocal lattice vectors. ${ }^{29}$

Minimum Energy Technique Applied to Dislocations, Interfaces and Surface Energies (METADISE) code ${ }^{30}$ was used to create (100), (101), and (110) surfaces from the bulk zabuyelite structure. The METADISE code ensures the creation of surfaces with zero dipole moment perpendicular to the surface plane. ${ }^{31}$ However, because of the adsorption of charged species, we have applied the Makov-Payne dipole correction perpendicular to the surface in all surface calculations, as implemented in the VASP code, ${ }^{32}$ to ensure that there is no net charge or monopole/dipole perpendicular to the surfaces, which might otherwise affect the adsorption energetics and structures. The constructed surfaces were expressed in periodic slabs of thickness $\geq 10 \AA$ to exclude interactions of surface rearrangement through the bulk. A vacuum of $15 \AA$ was introduced in the $z$-direction to prevent interactions between two consecutive slabs. For each surface, freshly cleaved surfaces with different terminations along the same crystallographic direction were subjected to energy minimization to determine the surface stability. The lowest surface energy under dry conditions $\left(\gamma_{\mathrm{r}, \mathrm{dry}}\right)$ calculated using eq 1 was used to identify the most stable termination.

$$
\gamma_{\mathrm{r}, \mathrm{dry}}=\frac{E_{\text {surf }}-x E_{\text {bulk }}}{2 A}
$$

Here $E_{\text {surf }}$ is the energy of the relaxed slab, $E_{\text {bulk }}$ is the energy of bulk $\mathrm{Li}_{2} \mathrm{CO}_{3}$ calculated by optimizing the bulk structure, $x$ is the equivalent number of the bulk $\mathrm{Li}_{2} \mathrm{CO}_{3}$ units in the slab, and $2 \mathrm{~A}$ the surface areas of both exposed surfaces of the cleaved crystal. For each surface, the termination with the lowest surface energy is considered most stable and used in further investigations. To mimic the natural environment in which adsorption takes place, water was introduced to the top surfaces of zabuyelite considering both physisorbed and chemisorbed adsorption configurations. The chemisorbed structures are found to be generally thermodynamically more favorable/preferred over the physisorption structures. In most cases for water adsorption, even when the initial, guessed structure is placed at $5 \AA$ above surface $\mathrm{Li}$ sites (physisorption), the water molecules move toward to surface sites forming chemisorbed structures during energy minimization. We, therefore, expect that physisorbed structures may only become feasible/stable at higher coverages (e.g., second layer of water). As only the top surface of the slab is hydrated, while the bottom surface remains "dry", the additional energy due to hydration of the surface at the top of the slab must be separated from the energy of the nonhydrated surface at the bottom. From the dry surface energy obtained from eq 1 , it is possible to calculate the wet surface energy $\left(\gamma_{\text {wet }}\right)$ from the total energy of the hydrated slab as shown in eq 2.

$$
\gamma_{\text {wet }}=\frac{E_{\text {surf }+ \text { water }}-x E_{\text {bulk }}-n E_{\text {water }}}{A}-\gamma_{\mathrm{r}, \mathrm{dry}}
$$

where $n E_{\text {water }}$ is energy of a $\mathrm{n}$ water molecules in a vacuum, obtained in a cubic box of size $15 \AA$, considering a $1 \times 1 \times 1$ Monkhorst-Pack K-points mesh. The initial adsorption geometries of the adsorbates (cations/anions) at the hydrated surfaces were generated manually and subsequently subjected to energy minimization in order to determine lowest-energy adsorption configurations. As the adsorption of cations/anions on the hydrated $\mathrm{Li}_{2} \mathrm{CO}_{3}$ surfaces can change the surface energies and, therefore, modulate the equilibrium morphology, we have also calculated the surface energies of the surfaces after the cations/anions adsorption using eq 3.

$$
\begin{aligned}
\gamma_{\text {adsorbed }}= & \frac{E_{\text {wet }- \text { surf }+m(\text { adsorbate })}-x E_{\text {bulk }}-n E_{\text {water }}-m E_{\text {ads }}}{A} \\
& -\gamma_{\mathrm{r}, \text { dry }}
\end{aligned}
$$

where $E_{\text {wet-surf } m \text { (adsorbate) }}$ is the total energy of the hydrated surface with $m$ adsorbed cations/anions. The energy of all monatomic adsorbates was obtained from optimizing their bulk materials using 7 $\times 7 \times 7$ mesh of K-points. We constructed the equilibrium crystal morphology for dry and wet $\mathrm{Li}_{2} \mathrm{CO}_{3}$ as well as those for $\mathrm{Li}_{2} \mathrm{CO}_{3}$ after cations/anions adsorption using the calculated surface energies and the Wulff construction procedure. ${ }^{33}$ The GDIS software was employed for the construction of the equilibrium crystal morphology $\mathrm{Li}_{2} \mathrm{CO}_{3}$. To characterize the strength of adsorption of each adsorbate on the different surfaces of $\mathrm{Li}_{2} \mathrm{CO}_{3}$, we calculated the average energies of adsorption $\left(E_{\text {ads }}\right)$ using eq 4.

$$
E_{\text {ads }}=\frac{1}{n}\left[E_{\text {surface }+n(\text { adsorbate })}-\left(E_{\text {surface }}+n E_{\text {adsorbate }}\right)\right]
$$

By this definition, a negative value of $E_{\text {ads }}$ corresponds to an exothermic and favorable adsorption process, whereas a positive value indicates an endothermic and unfavorable adsorption.

\section{RESULTS}

3.1. Interactions between Different Components in Solution. Supersaturation with respect to mineral phases can be altered by the complexation of ions in solution. ${ }^{13,14}$ The PHREEQC speciation simulations predict that $27 \%$ of the carbonate present in the system studied here is incorporated into $\mathrm{Na}$-carbonate ion pairs in the $\mathrm{LiBr}-\mathrm{Na}_{2} \mathrm{CO}_{3}$ solutions at $20{ }^{\circ} \mathrm{C}$. At the same temperature, the number of ion pairs 
between $\mathrm{Na}$ and carbonate increases to $76 \%$ and $32 \%$ in the 1 and $0.1 \mathrm{M} \mathrm{NaCl}$ solutions, respectively. Elevating the solution temperature to $80{ }^{\circ} \mathrm{C}$ is expected to make the ion pair formation less thermodynamically favorable with only $9 \%$ of carbonate occupying these ion pairs in the $\mathrm{LiBr}-\mathrm{Na}_{2} \mathrm{CO}_{3}$ and $\mathrm{NaCl}$ solutions at this temperature. No ion pairs were predicted in the presence of $\mathrm{K}^{+}$, as there is no thermodynamic data available for these species. This is consistent with the absence of experimental evidence for the formation of $\mathrm{K}$ carbonate contact ion pairs and our solution concentration, which was lower than that required to form solvent mediated ion pairs. ${ }^{34}$ Only Li-chloride and Li-sulfate ion pairs can be modeled using the llnl database. When $1 \mathrm{M}$ of $\mathrm{Cl}$ is present, $1.5 \%$ of $\mathrm{Li}$ in solution is predicted to form an ion pair with $\mathrm{Cl}^{-}$. These ion pairs are expected to increase to $2.5 \%$ of the total $\mathrm{Li}^{+}$ in the experiments at $80{ }^{\circ} \mathrm{C}$. In contrast, $12 \%$ of $\mathrm{Li}^{+}$is predicted to form Li-sulfate ion pairs with the highest concentration of sulfate in solution. As for the carbonate ion pairs with $\mathrm{Na}^{+}$, the Li-sulfate ion pairs are expected to be less favorable at higher temperatures, with $10 \%$ of the $\mathrm{Li}^{+}$ occupying these complexes at $80{ }^{\circ} \mathrm{C}$.

To determine whether the formation of ion pairs was significant in our experiments, we examined changes in the symmetrical stretch band for sulfate $\left(985 \mathrm{~cm}^{-1}\right)^{24}$ and carbonate $\left(1067 \mathrm{~cm}^{-1}\right)^{34}$ in different solutions. Positions for the sulfate and carbonate Raman bands in the solutions are listed in the Supporting Information Table S1. The main carbonate band in the $\mathrm{Na}_{2} \mathrm{CO}_{3}$ solution was observed at 1067 $\mathrm{cm}^{-1}$. Similarly, the carbonate band was observed at $1067 \mathrm{~cm}^{-1}$ in aqueous solutions equilibrated with Li-carbonate; however, a shoulder was also observed in some of the Raman spectra (Figure 1a). The shoulder band at $1076 \mathrm{~cm}^{-1}$ decreased in intensity with increasing concentrations of Li-carbonate in solution. In repeated equilibration experiments, the shoulder band was no longer detectable indicating a higher concentration of $\mathrm{Li}^{+}$and $\mathrm{CO}_{3}{ }^{2-}$ in solution. Increasing the temperature of the solution did not change the center position or full width half maximum (FWHM) of the carbonate band in these solutions. This is similar to the lack of change in the band center and FWHM with temperature for the $\mathrm{Na}_{2} \mathrm{SO}_{4}$ solution. In the presence of $\mathrm{LiBr}$, however, the $\mathrm{SO}_{4}{ }^{2-}$ symmetrical stretch increased in FWHM with increasing temperature but did not systematically change its center position. Increasing temperature also produced a decreasing ratio between bands associated with the tetrahedral structure (3050 and 3255 $\mathrm{cm}^{-1}$ ) and hydrogen bonding network (3393, 3511, and 3628 $\left.\mathrm{cm}^{-1}\right)^{35,36}$ of water in all solutions studied. However, the Libearing solutions show a lower ratio than would be expected based on the ionic strength of the solution (Figure 1b).

3.2. Precipitation Experiments. 3.2.1. Experiments without Additional lons. A white precipitate was observed to form within $3 \mathrm{~min}$ after the Li-bearing and carbonate solutions were mixed. XRD identified the precipitates as zabuyelite, and DRIFTS analysis of the bulk precipitate (Figure 2a) confirmed that our precipitates were consistent with zabuyelite precipitated using $\mathrm{LiCl}^{20}$ SEM images of the precipitates show that the crystals formed a consistently prismatic morphology (average length: $9 \mu \mathrm{m}$ ) with one elongated axis (Figure 3a), in agreement with previous synthesis experiments. ${ }^{37}$ One terminus of the elongation axis was observed to have a rough appearance. Closer inspection of the images revealed that this is probably related to the formation of rosettes, where the center of the rosette is hollow,
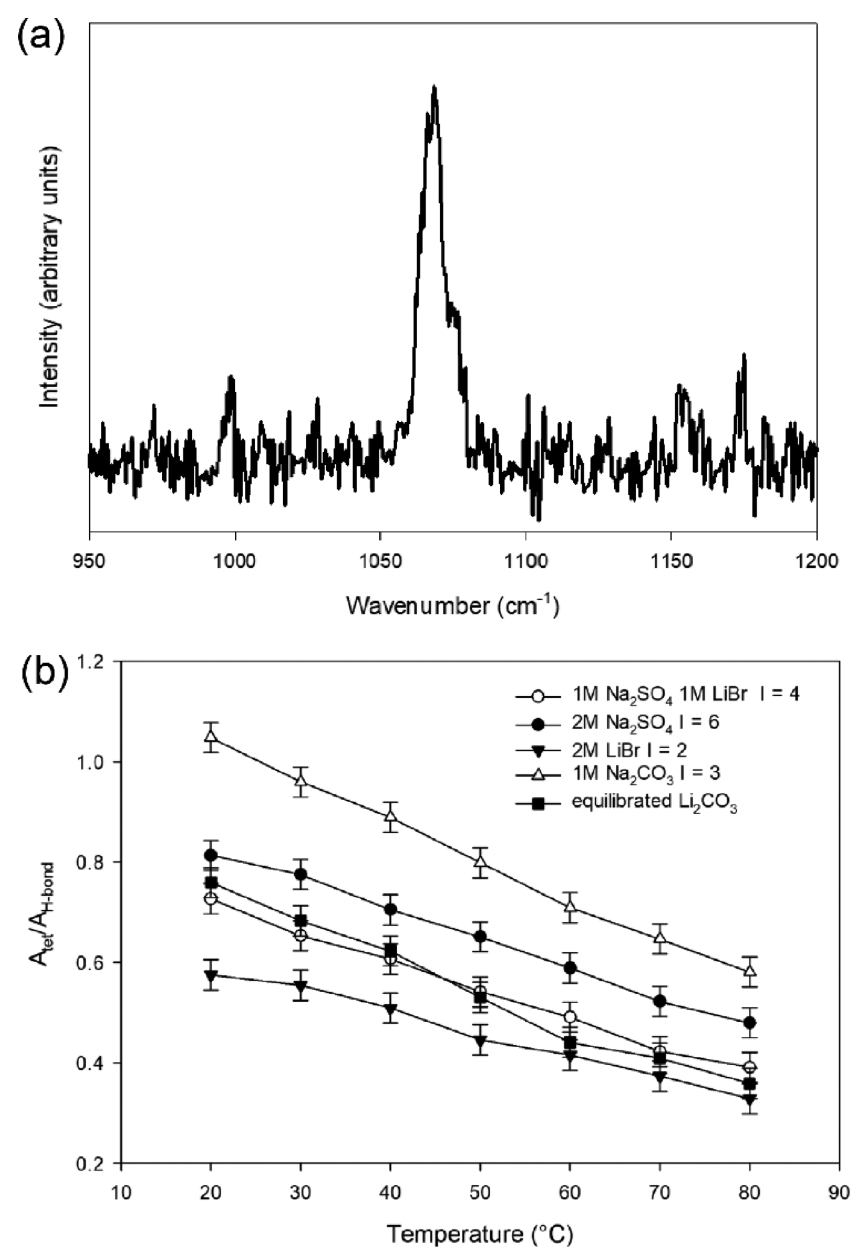

Figure 1. (a) Raman spectrum of carbonate symmetrical stretching band with shoulder at higher wavenumbers taken from a water solution equilibrated with zabuyelite at room temperature. (b) Change with temperature of area under Raman bands that are related to tetrahedral structure $\left(A_{\text {tet }}\right)$ and H-bonding $\left(A_{\mathrm{H}-\text { bond }}\right)$ of water in different solutions. $I$ indicates the ionic strength of the different solutions.

and crystals show a similar texture at their terminus. Raman spectroscopy of single crystals confirmed the identification of zabuyelite through the characteristic carbonate symmetrical stretching band at $1093 \mathrm{~cm}^{-138}$ as well as the number and position of the low wavenumber bands (Figure $2 \mathrm{~b}$ ). Relative intensities of the Raman bands were observed to vary between the crystals sampled, probably due to orientation effects. ${ }^{39}$

3.2.2. Solutions with Monovalent Chloride Salts. As observed for the experiments conducted with only $\mathrm{LiBr}$ and $\mathrm{Na}_{2} \mathrm{CO}_{3}$, precipitation occurred within the first $3 \mathrm{~min}$ after the addition of the carbonate solution for the experiments with 1 $\mathrm{M} \mathrm{KCl}$ solution. However, in the presence of $1 \mathrm{M} \mathrm{NaCl}$ nucleation only occurred after six minutes. Bulk analysis of the precipitates using DRIFTS and XRD demonstrated that zabuyelite was also formed in these experiments (Figure 2a). Similarly, SEM imaging of the precipitates shows that the crystals expressed a very similar prismatic crystal morphology (Figure $3 c, d$ ) to the experiments without additional ions and are also found as rosettes. However, measurements of crystal aspect components indicate that the $\{010\}$ forms are enlarged in the presence of $\mathrm{NaCl}$ and $\mathrm{KCl}$. This occurred at the expense of $\{110\}$ form width in comparison to crystals grown in 


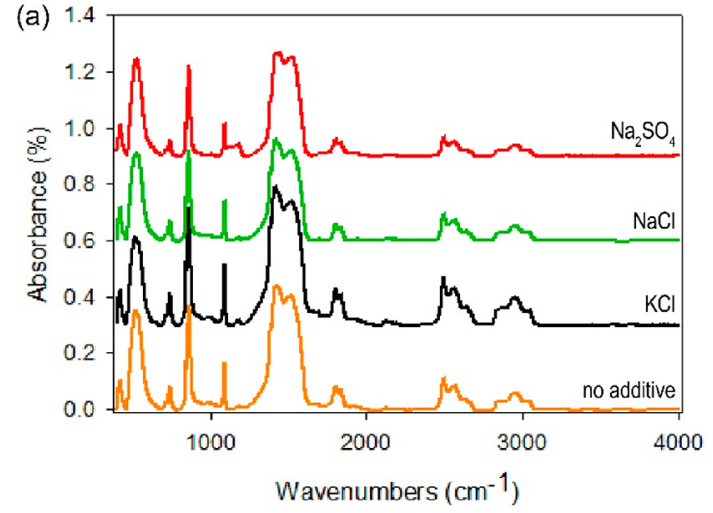

(b)
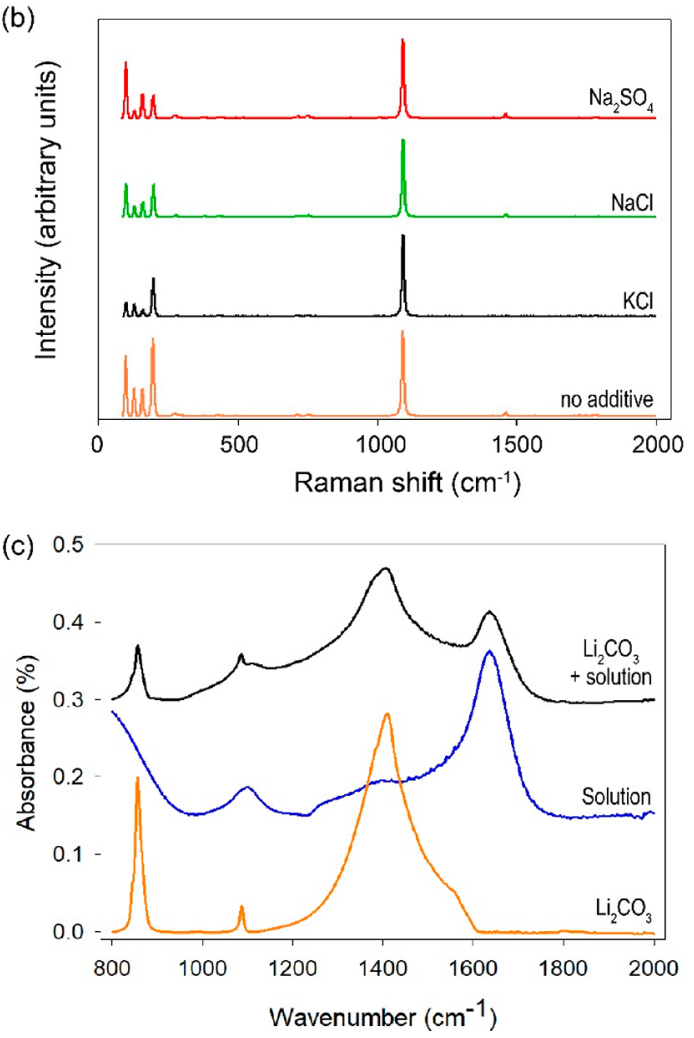

Figure 2. Vibrational spectroscopy of samples. (a) Diffuse reflectance Infrared Fourier transform spectroscopy (DRIFTS) of solids produced without additives, in the presence of $1 \mathrm{M} \mathrm{KCl}$ or $\mathrm{NaCl}$, or $0.33 \mathrm{M} \mathrm{Na}_{2} \mathrm{SO}_{4}$ (1 $\mathrm{M}$ ionic strength). (b) Raman spectra of crystals from experiments in (a). (c) Attenuated total reflectance infrared (ATR-IR) spectroscopy testing the adsorption of sulfate to zabuyelite crystals produced in additive free solutions (labeled $\mathrm{Li}_{2} \mathrm{CO}_{3}+$ solution). $\mathrm{Li}_{2} \mathrm{CO}_{3}$ spectrum shows the dry crystals before the experiment and "solution" shows the $0.33 \mathrm{M} \mathrm{Na}_{2} \mathrm{SO}_{4}$ solution spectrum. Spectra are offset for clarity.

solutions containing only $\mathrm{LiBr}$ and $\mathrm{Na}_{2} \mathrm{CO}_{3}$ (Table 2, Figure 3 ). In addition, the average length of the crystals increased to $15 \mu \mathrm{m}$. Raman spectroscopic analysis showed spectral bands at the same positions as those detected in the $\mathrm{LiBr}$ with $\mathrm{Na}_{2} \mathrm{CO}_{3}$ experiments. No difference in the FWHM $\left(8.7 \pm 0.2 \mathrm{~cm}^{-1}\right)$ of the most intense Raman band at $1093 \mathrm{~cm}^{-1}$ was observed between experiments with and without high concentrations of the monovalent cation chloride salts, implying that the crystals had a similar crystallinity. ${ }^{40}$ However, the lower concentration of $\mathrm{KCl}$ led to an increase in the FWHM of the carbonate symmetrical stretch to $9.4 \pm 0.5 \mathrm{~cm}^{-1}$.
3.2.3. Solutions with Divalent Cation Chloride Salts. In contrast to the monovalent cation chloride salts, in the $\mathrm{CaCl}_{2}$ and $\mathrm{MgCl}_{2}$ experiments there is a significant shift of the band close to $1090 \mathrm{~cm}^{-1}$ in the FTIR spectra to lower and higher wavenumbers, respectively (Figure 4a). Similarly, the more dominant FTIR bands in the $1400 \mathrm{~cm}^{-1}$ region are different in relative intensity and position for the precipitates from solutions containing $\mathrm{Ca}$ and $\mathrm{Mg}$ in comparison to those produced in experiments with $\mathrm{NaCl}$ or $\mathrm{KCl}$. Bands in this region correspond to the carbonate asymmetric stretch, ${ }^{41}$ indicating that in the $\mathrm{Ca}$ - and $\mathrm{Mg}$-bearing solutions, different carbonate phases were formed. A broad area with multiple IR bands close to $1500 \mathrm{~cm}^{-1}$ is consistent with the formation of calcite in the $\mathrm{CaCl}_{2}$ solutions, whereas the presence of three distinct bands at around $1500 \mathrm{~cm}^{-1}$ and particularly the sharp IR band close to $3600 \mathrm{~cm}^{-1}$, indicates that the phase precipitated in the $\mathrm{MgCl}_{2}$ experiments is a hydrated $\mathrm{Mg}$ carbonate. The production of a different phase is confirmed in the SEM images (Figure $4 b, c$ ), where two distinct crystal morphologies can be observed in the $\mathrm{CaCl}_{2}$ solution experiments and only platy crystals are observed with both concentrations of $\mathrm{MgCl}_{2}$. In the experiments with the higher $\mathrm{CaCl}_{2}$ concentration (equivalent to $1 \mathrm{M}$ ionic strength), the crystals showed a high degree of porosity and appear to be an assembly of many smaller particles (Figure $4 \mathrm{~b}$ ). Between these porous crystals, 5-10 $\mu \mathrm{m}$ long crystals with well-defined crystal faces and a more rhombohedral morphology were also observed. EDX spectroscopy of the crystals showed that both contained $\mathrm{Ca}$, consistent with the identification of calcite using $\mu$ m-resolved Raman spectroscopy of the precipitated crystals with different morphologies. Lowering the $\mathrm{CaCl}_{2}$ concentration produced very similar crystal morphologies to those observed in the $\mathrm{KCl}$ and $\mathrm{NaCl}$ experiment, as well as flat crystals with a 3-6-fold rotational symmetry (Figure 3b). EDX spectroscopic analysis of the flat crystal showed that they contained $\mathrm{Ca}$ and were later identified as calcite based on their Raman spectrum. In contrast, the prismatic crystals were identified as zabuyelite. The Raman spectra for the platy crystals from the $\mathrm{MgCl}_{2}$ experiments showed bands of the hydrated $\mathrm{Mg}$-carbonate phase dypingite $\left(\mathrm{Mg}_{5}\left(\mathrm{CO}_{3}\right)_{4}(\mathrm{OH})_{2}\right.$. $\left.5\left(\mathrm{H}_{2} \mathrm{O}\right)\right)^{42}$ (not shown). Analysis of the Raman spectra show that the FWHM of the carbonate symmetrical stretch from zabuyelite increased to $9.5 \pm 0.3 \mathrm{~cm}^{-1}$ when $\mathrm{Ca}^{2+}$ was present in the solution. PHREEQC simulations predict the formation of calcite and magnesite in the experiments.

3.2.4. Solutions with Sulfate. Experiments conducted in the presence of sulfate also produced only zabuyelite crystals, as identified with XRD, DRIFTS, and Raman spectroscopy (vibrational spectroscopy results shown in Figure 2a,b). As for the $1 \mathrm{M} \mathrm{NaCl}$ solution, nucleation in these experiments was observed to be slower than in the absence of additives. These crystals also had a morphology similar to the crystals observed with monovalent chloride salts and a similar length $(10 \mu \mathrm{m})$ to those produced in $\mathrm{LiBr}$ with $\mathrm{Na}_{2} \mathrm{CO}_{3}$ experiments (Figure $3 \mathrm{e}$ ). However, for these crystals the $\{010\}$ form was observed to decrease in size (Table 2), and thin $\{100\}$ forms were also expressed. In addition, some crystals showed evidence of rounded channels penetrating the crystal along its elongation axis (arrow in Figure 3e). Rosettes were also observed in the sulfate experiments. An increase in the FWHM of the 1093 $\mathrm{cm}^{-1}$ carbonate symmetrical stretching band to $9.3 \pm 0.3 \mathrm{~cm}^{-1}$ was also seen in the Raman spectra when sulfate was present in the growth solution. In addition, the FWHM of the $31^{\circ}$ peak in 

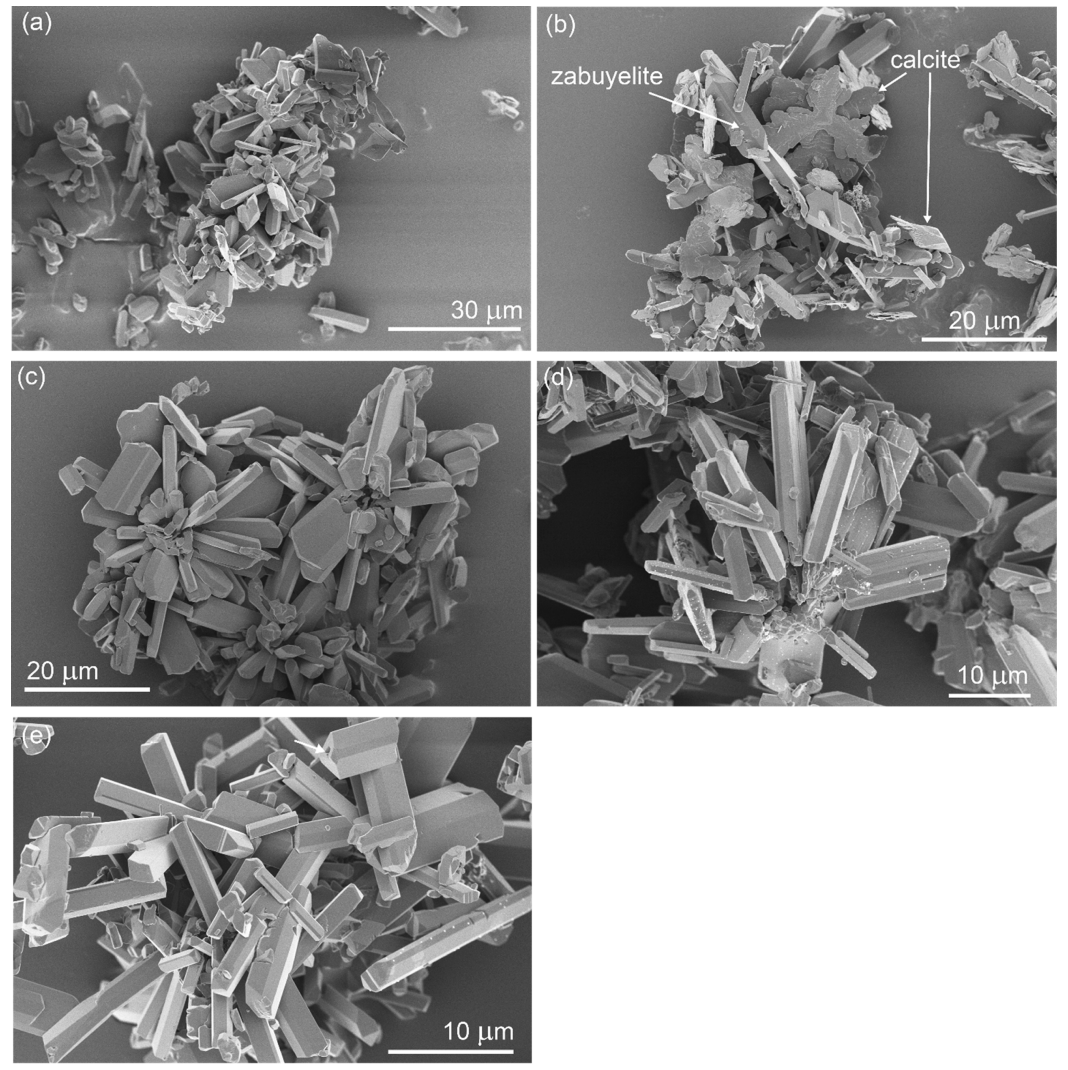

Figure 3. Zabuyelite crystals grown in (a) $\mathrm{LiBr}+\mathrm{Na}_{2} \mathrm{CO}_{3}$ solution with no additional ions and in the presence of (b) $0.033 \mathrm{M} \mathrm{CaCl}$. Note: $0.33 \mathrm{M}$ solutions produced only calcite, (c) $1 \mathrm{M} \mathrm{KCl}$, (d) $1 \mathrm{M} \mathrm{NaCl}$, and (e) $0.33 \mathrm{M} \mathrm{Na}_{2} \mathrm{SO}_{4}$.

Table 2. Aspect Ratios of the Crystals Grown in Different Solutions, Where $w$ Is the Entire Width of the Crystal, and $\mathbf{w}_{\{010\}}, \bar{w}_{\{110\}}$ Refer to the Width of the $\{010\}$ and Mean Width of the $\{110\}$ Forms Viewable Perpendicular to the $b$ Axis, Respectively ${ }^{a}$

\begin{tabular}{ccccc}
\multicolumn{1}{c}{ solution } & $\mathrm{w}_{\{010\}} / \mathrm{w}$ & $\mathrm{SD}$ & $\bar{w}_{\{110\}} / \mathrm{w}$ & $\mathrm{SD}$ \\
$\mathrm{LiBr}+\mathrm{Na}_{2} \mathrm{CO}_{3}$ & 0.3 & 0.1 & 0.3 & 0.04 \\
$1 \mathrm{M} \mathrm{NaCl}$ & 0.6 & 0.2 & 0.2 & 0.07 \\
$1 \mathrm{M} \mathrm{KCl}$ & 0.7 & 0.1 & 0.2 & 0.05 \\
$0.033 \mathrm{M} \mathrm{CaCl}$ & 0.3 & 0.1 & 0.4 & 0.05 \\
$0.33 \mathrm{M} \mathrm{Na}_{2} \mathrm{SO}_{4}$ & 0.2 & 0.1 & 0.4 & 0.06 \\
${ }^{a} \mathrm{SD} \mathrm{=} \mathrm{standard} \mathrm{deviation} \mathrm{at} 1 \sigma$. & & &
\end{tabular}

the XRD was also found to increase in comparison to the $\mathrm{LiBr}$ with $\mathrm{Na}_{2} \mathrm{CO}_{3}$ experiments. However, the FWHM value was similar to those observed in the $\mathrm{NaCl}$ experiments, which showed no increase in the FWHM of the carbonate symmetrical stretch in the Raman spectra.

3.3. Adsorption of lons to Li Carbonate Surfaces. 3.3.1. Bulk and Surface Characterization of Zabuyelite in Computational Simulations. Optimized lattice parameters from DFT calculations show a high agreement with the values determined by neutron powder diffraction of Idemoto et al. ${ }^{28}$ Calculated values of the lattice parameters and band gap along with previous calculations available in the literature can be found in the Supporting Information Table S2. The symmetrical up and down density of states (Figure S1) and calculated band gap of $4.9 \mathrm{eV}$ are also in agreement with previous studies indicating zabuyelite is a nonmagnetic insulator.
Several zabuyelite surface terminations were examined for the (001), (101), and (110) surfaces to determine the most stable atomic configurations (Table 3). For all three surfaces, the most stable plane of bulk zabuyelite reduces the originally tetrahedrally coordinated $\mathrm{Li}$ ions to 3 -fold coordination. The stability order of the zabuyelite surfaces in dry conditions was calculated to be $(001)>(\overline{1} 01)>(110)$. Water adsorption lowered the energy of the system (Table 4) and thus produced more stable surfaces than those observed in vacuo due to a similar $\mathrm{Li}$ coordination to that observed in the bulk structure (Figure 5). This behavior has been found previously in calculations of hydrated, relaxed surfaces on calcite, where oxygen atom of the water molecules coordinates to the surface calcium, stabilizing the surface. ${ }^{43}$ Relaxation of the hydrated surface led to a reversal of the stability order: $(110)>(\overline{101})>$ (001). Wulff constructed equilibrium morphologies of the entire crystal based on the calculated surface energies predicts that zabuyelite in a vacuum has a broad, plate-like structure with equal contributions from the (001), (101), and (110) surfaces in agreement with previous computational work using ab initio modeling. ${ }^{37}$ However, the equilibrium morphology expected for hydrated surfaces is very similar to the prismatic crystal observed in the experiments (c.f., Figures $5 \mathrm{~b}$ and $6 \mathrm{a}$ ) indicating a good representation of surface stability is provided by the simulations.

3.3.2. Adsorption of Monovalent lons: $\mathrm{K}^{+}, \mathrm{Na}^{+}$, and $\mathrm{Cl}^{-}$. Sodium and potassium show similar behavior when they are adsorbed onto zabuyelite surfaces (Figure $6 \mathrm{~b}, \mathrm{c}$ ). On the (001) and (101) surfaces, the cations align themselves between the rows of water molecules. The channels in which the adsorbates position themselves are parallel with the $a$ and $b$ crystal axis on 

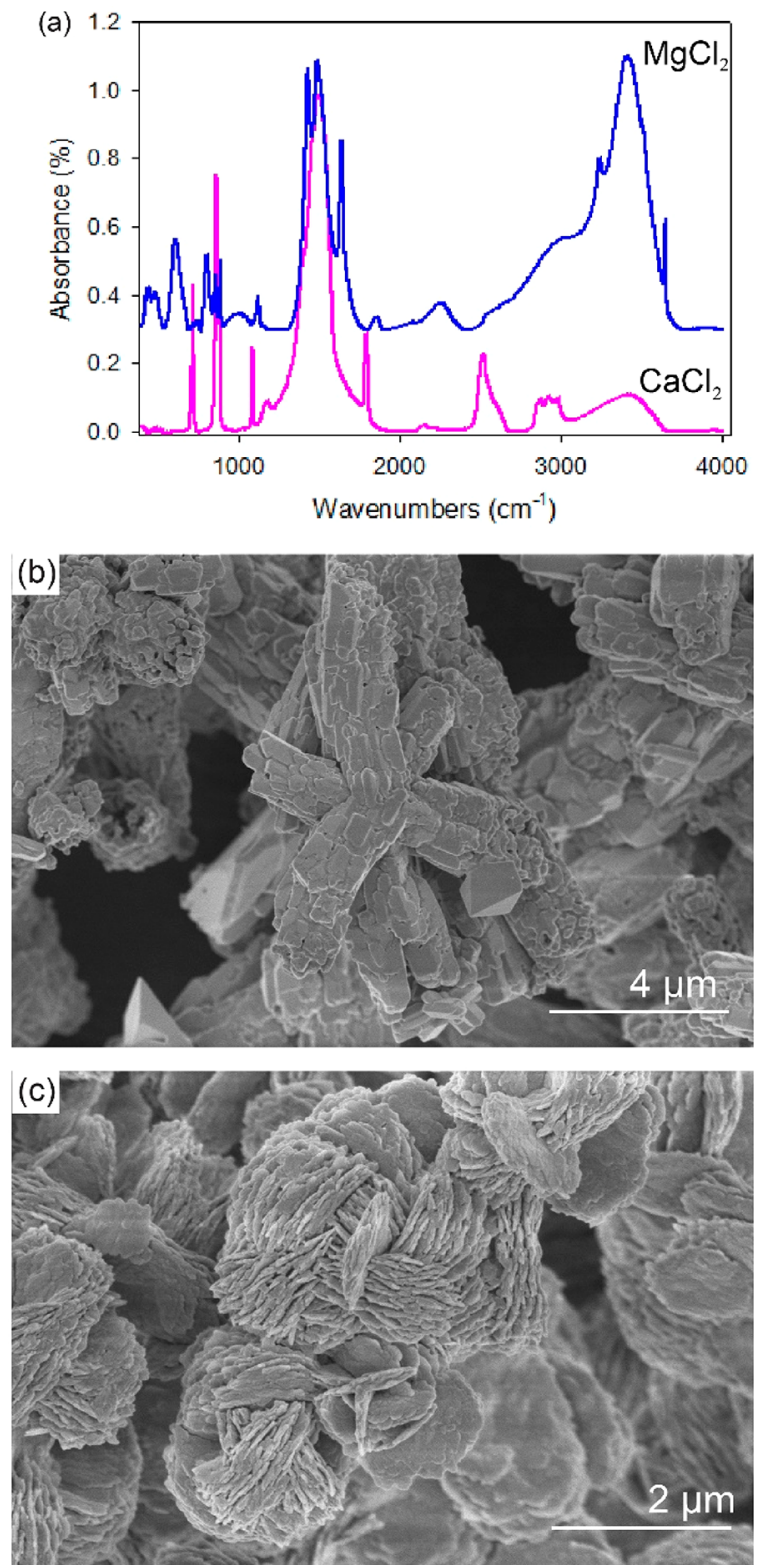

Figure 4. (a) DRIFTS spectra of the solids formed in the experiments with $0.33 \mathrm{M} \mathrm{MgCl}_{2}$ and $\mathrm{CaCl}_{2}$ solutions. The spectra are offset for clarity. (b) Secondary electron images of crystals formed in zabuyelite growth solutions with $0.33 \mathrm{M} \mathrm{CaCl}_{2}$, and (c) precipitates from zabuyelite growth solutions with $0.33 \mathrm{M} \mathrm{MgCl}_{2}$.

Table 3. Surface Stabilities of Different Surface Terminations $^{a}$

\begin{tabular}{ccccc} 
& \multicolumn{4}{c}{$\gamma_{\text {dry }}$} \\
\cline { 2 - 5 } surface & Li CN:3 & $\mathrm{C}-\mathrm{O}$ & $\mathrm{Li} \mathrm{CN}: 1 / 2$ & $\mathrm{C} \mathrm{CN}: 2$ \\
$(001)$ & 0.358 & 2.648 & & \\
$(\overline{1} 01)$ & 0.484 & & & \\
$(110)$ & 0.720 & & 1.913 & 3.386 \\
${ }^{a} \mathrm{CN}=$ coordination number. & & \\
\hline
\end{tabular}

the (101) and (001) surfaces, respectively. On the (110) surface, $\mathrm{Na}^{+}$and $\mathrm{K}^{+}$adsorb at similar positions; however, instead of occupying channels between the water molecules at the surface, the ions are positioned above the water molecules and the water molecules rotate at the surface so that the $\mathrm{H}$ atoms lie parallel to the surface. This rotation allows the $\mathrm{O}$ atoms of the water molecules to interact with the adsorbing cations and $\mathrm{Li}$ ions within the (110) surface. Similarly, $\mathrm{Cl}^{-}$ adsorbs to the (001) surface between the water molecule channels aligned parallel the $b$ axis of the crystal (Figure 6d). The (110) surface also shows similar behavior for $\mathrm{Cl}^{-}$and the monovalent, monatomic cations, where the anion positions itself above the water molecules at the surface. However, because of the negative charge of the $\mathrm{Cl}^{-}$ions the water molecules closest to the anion interact via their $\mathrm{H}$ rather than $\mathrm{O}$ atom. The main difference between the adsorption of monovalent, monatomic cations and anions is found on the (101) surface. Here, the chlorine anions also positioned themselves above the water molecules. Complexation of the monovalent ions at the crystal surfaces changes the surface stability further than water adsorption to the surface. The equilibrium morphology of the crystal remains elongated, with $\{110\}$ faces at the crystal edges, but for the adsorption of $\mathrm{Cl}^{-}$ the (001) surface area becomes much more limited.

3.3.3. Adsorption of Divalent lons: $\mathrm{Mg}^{2+}$ and $\mathrm{SO}_{4}{ }^{2-}$. Magnesium adsorbs at similar surface locations to those observed with $\mathrm{Na}^{+}$and $\mathrm{K}^{+}$on the (001) and (110) surfaces (Figure 6e). However, unlike the simulations with $\mathrm{Na}^{+}$and $\mathrm{K}^{+}$, on the (101) surface, the $\mathrm{Mg}^{2+}$ does not align along a single plane above the surface. Instead it organizes itself into a staggered configuration. Additionally, the $\mathrm{Mg}^{2+}$ displaces the water molecules at this surface, increasing the bond length between the water oxygen and $\mathrm{Li}^{+}$atoms to $2.289 \AA$, compared to $2.033 \AA$ without $\mathrm{Mg}^{2+}$ ions. Change in the strength of the water-Li interaction is reflected in the surface energies, where the presence of $\mathrm{Mg}^{2+}$ increased the hydrated (101) and (110) surface energies from 0.204 and 0.059 with $\mathrm{Na}^{+}$to 0.894 and 0.882 , respectively. Lowering the stability difference between these faces is expressed as a similar size of the (101) and (110) faces on the equilibrium crystal morphology when $\mathrm{Mg}^{2+}$ is present. Thus, the hydrated zabuyelite crystal interacting with the $\mathrm{Mg}^{2+}$ ions is predicted to adopt a morphology similar to that expected in vacuo.

Sulfate $\left(\mathrm{SO}_{4}{ }^{2-}\right)$ has two under-coordinated oxygen atoms; thus this oxyanion can compete with water molecules for the under-coordinated lithium binding sites at the zabuyelite surface. Due to its shape, more than one sulfate $\mathrm{O}$ atom can form an interaction with the $\mathrm{Li}$ atoms at the zabuyelite surface, i.e., as either monodentate mononuclear (MM) or bidentate binuclear (BB) adsorption complexes. The time scale of the simulations does not allow us to test what happens when sulfate approaches the surface and displaces the water molecules. Therefore, we have compared the energies generated through adsorption of sulfate and water in vacuo to determine if sulfate adsorption is more favorable than water and thus will displace water during adsorption. On all three surfaces, the distance between $\mathrm{Li}$ atoms at the surface is favorable for sulfate complex formation. Monodentate mononuclear adsorption complexes were found to be less energetically favorable compare to $\mathrm{BB}$ adsorption consistent with previous work. ${ }^{44,45}$ The optimized BB adsorption complexes of sulfate on zabuyelite (001), (101), and (110) surfaces are shown in Figure 6f, whereas the calculated adsorption energies and surface energies of water and sulfate covered surfaces are summarized in Table 4 . The adsorption energies of sulfate on all three surfaces are more negative than the adsorption of water, suggesting that sulfate will outcompete water for the under-coordinated lithium binding sites at the 
Table 4. Adsorption Energies Calculated for Different Brine Components and the Resultant Change in Surface Energies

\begin{tabular}{|c|c|c|c|c|c|c|c|c|}
\hline surface & $E_{\text {ads } \mathrm{H}_{2} \mathrm{O}}$ & $E_{\text {ads } \mathrm{SO}_{4}}$ & $\gamma_{\text {wet }}$ & $\gamma_{\mathrm{Na}}$ & $\gamma_{\mathrm{K}}$ & $\gamma_{\mathrm{Mg}}$ & $\gamma_{\mathrm{Cl}}$ & $\gamma_{\mathrm{SO}_{4}}$ \\
\hline$(001)$ & -0.44 & -1.10 & 0.026 & 0.259 & 0.232 & 1.108 & 0.394 & -0.065 \\
\hline$(\overline{1} 01)$ & -0.51 & -1.10 & 0.075 & 0.204 & 0.173 & 0.894 & 0.507 & 0.046 \\
\hline$(110)$ & -0.85 & -1.61 & -0.245 & 0.059 & -0.173 & 0.882 & 0.082 & 0.261 \\
\hline
\end{tabular}

(a)

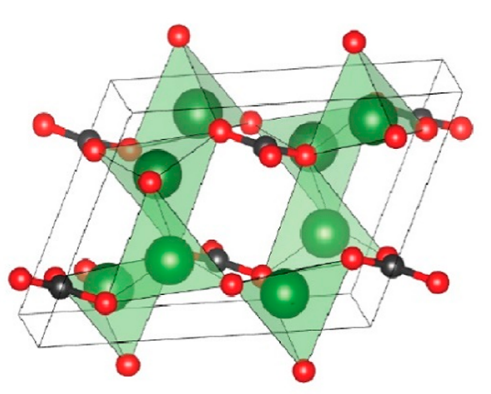

(b)

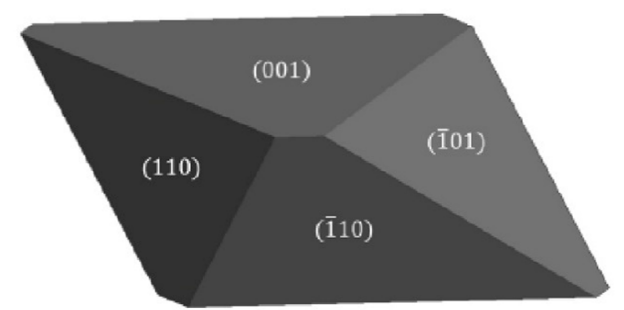

Figure 5. Computational simulations of zabuyelite. (a) Bulk structure of zabuyelite, where the green sphere: $\mathrm{Li}$, black spheres: $\mathrm{C}$ and red spheres: O. The green polyhedra show the tetrahedral Li sites. (b) Predicted equilibrium morphology of the dry zabuyelite crystal in vacuo based on the surface energies of the most stable surfaces.

zabuyelite surfaces. As for $\mathrm{Mg}^{2+}$, adsorption of sulfate produced a predicted equilibrium morphology similar to that observed in vacuo (Figure $5 b$ ).

3.3.4. Verification of Adsorption Using ATR-IR. Adsorption of monatomic ions to the zabuyelite surface would not be expected to produce their own bands in the IR spectrum. However, changing the chemistry of carbonate nearest cation neighbors produces a measurable difference in the stretching modes of carbonate. ${ }^{46}$ Therefore, the spectral position of the carbonate asymmetrical stretch was assessed using ATR-IR. Sulfate band positions were compared with a $0.33 \mathrm{M} \mathrm{Na}_{2} \mathrm{SO}_{4}$ solution without any zabuyelite (Figure $2 \mathrm{c}$ ). In all experiments, the same broad bands were observed at 740, 858, 1087, and $1407 \mathrm{~cm}^{-1}$ in the solid phase consistent with the DRIFTS analysis. Sulfate in solution produced an intense band at 1096 $\mathrm{cm}^{-1}$ that is related to the asymmetrical stretch of the tetrahedral sulfate oxyanion. ${ }^{47}$ Zabuyelite crystals that are exposed to a $0.33 \mathrm{M}$ sulfate solution show a shift of this band to $1110 \mathrm{~cm}^{-1}$ (Figure 2c). No other evidence for adsorption was observed with the ATR-IR.

\section{DISCUSSION}

4.1. Li Carbonate Precipitation Mechanism. As for other crystalline carbonate materials such as calcite, $\mathrm{Li}_{2} \mathrm{CO}_{3}$ has an inverse solubility, whereby the solubility of the solid phase decreases with increasing temperature. ${ }^{48,49}$ The solubility limit of $\mathrm{Li}_{2} \mathrm{CO}_{3}$ at $25{ }^{\circ} \mathrm{C}$ has been experimentally determined as $0.017 \mathrm{M} .^{48}$ Thus, the inverse solubility expected for $\mathrm{Li}_{2} \mathrm{CO}_{3}$ and high concentration of $\mathrm{Li}^{+}$and carbonate in our solutions (both $0.5 \mathrm{M}$ ) should result in a very high supersaturation with respect to zabuyelite. In other carbonate systems, high supersaturation levels lead to the formation of amorphous precursor phases that transform into the final crystalline product. ${ }^{50}$ In our experiments, we do not see direct evidence for a precursor phase. However, we repeatedly observe that the rosette crystal arrangement produced throughout our experiments have a hollow core. This is unusual as rosettes are typically proposed to form due to structural interactions between the different crystal arms, such as aragonite rosettes formed in the presence of nonionic polymers. ${ }^{51}$ Similarly, in ice rosettes, whose crystals have a very similar shape to that of zabuyelite, the core is solid and connects the different crystal arms. ${ }^{26}$ In addition, we observe hollow structures penetrating into the center of individual crystals in the sulfate experiments (Figure 3e). A similar structure has also been observed in ice formation and is typically attributed to higher supersaturations. ${ }^{52}$ Recrystallization of less crystalline Ca-carbonate into a crystalline phase has been shown to form hollow structures in some experiments. ${ }^{53}$ Thus, the presence of channels within our crystals and hollow centers of the rosettes indicates that zabuyelite may also precipitate via transformation from a precursor phase.

4.2. Influence of Monovalent Ions on Li Carbonate Growth. Unlike zabuyelite, $\mathrm{Na}$ and K-carbonates have high solubility, which for K-carbonate increases with elevated temperature. ${ }^{54}$ The absence of these minerals in the precipitated phases is consistent with the expected higher thermodynamic stability of zabuyelite with respect to these phase. ${ }^{55}$ As $\mathrm{Na}^{+}$and $\mathrm{K}^{+}$will not compete directly for carbonate via the growth of additional solid phases, the main influence of these ions will be on the chemistry of the system. For example, Na-carbonate ion pairs were predicted based on the PHREEQC simulations. Incorporation of the mineral constituent ion into an ion pair with a nonconstituent ion can significantly lower the supersaturation of the solution with respect to the mineral of interest. ${ }^{13}$ Indeed, the time required for nucleation doubled in the presence of $1 \mathrm{M} \mathrm{NaCl}$ in comparison to the additive free experiments. However, the formation of rosettes with hollow cores indicates that the supersaturation remained high despite the formation of $\mathrm{Na}$ carbonate ion pairs.

The presence of background ions can have an indirect effect on the hydration of mineral constituent ions in solution. This may be important for $\mathrm{Li}$-carbonate growth as $\mathrm{Li}^{+}$is predicted to have a coherent first hydration shell due to the strong electrostatic fields that are expected for small cations ${ }^{\text {e.g., }} .56$ Of the monovalent, monatomic cations, $\mathrm{Li}^{+}$has the highest degree of covalent character in its interaction with the water molecules of its first hydration shell. ${ }^{57}$ This effect results in a shorter distance between the water molecules and $\mathrm{Li}^{+}$ions, thus large enthalpy of hydration. ${ }^{56}$ The presence of background ions is proposed to be able to disturb the hydration shell of ions facilitating nucleation and growth, known as "salting out". Such decreases in solubility can be observed in carbonate phases, such as calcite, at high ionic strengths of solution. ${ }^{58}$ In addition 


\section{Adsorbed} ions/molecules

(a)

Water

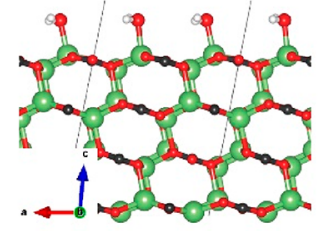

Monovalent

(b)

$\mathrm{Na}^{+}$

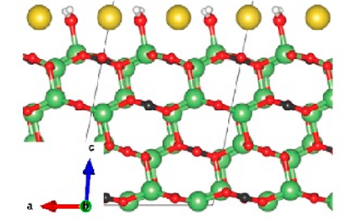

(c)

$\mathrm{K}^{+}$

(d)

$\mathrm{Cl}^{-}$
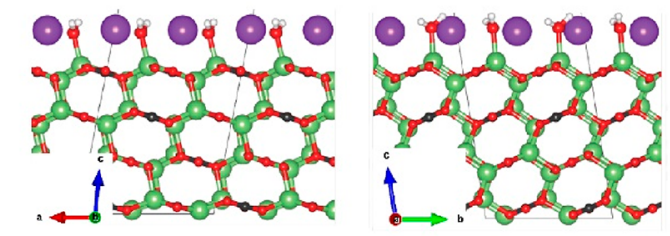

Divalent

(e)

$\mathrm{Mg}^{2+}$
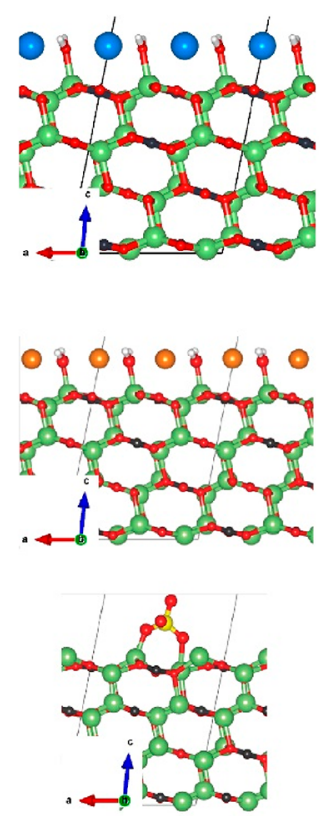
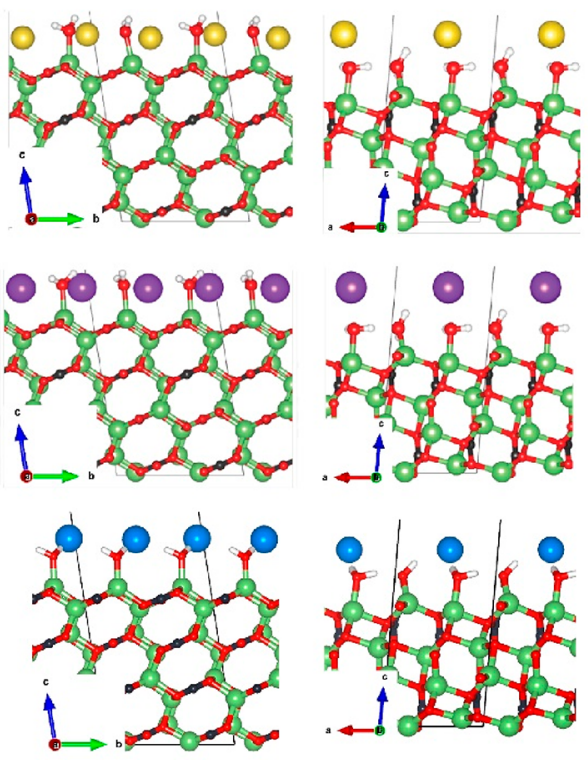

Surface

(101)

(110)
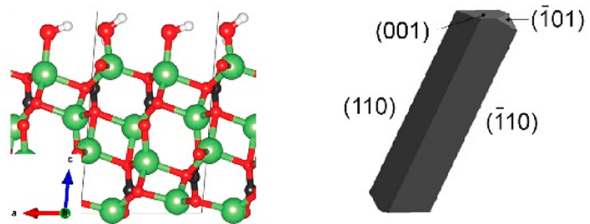

Morphology
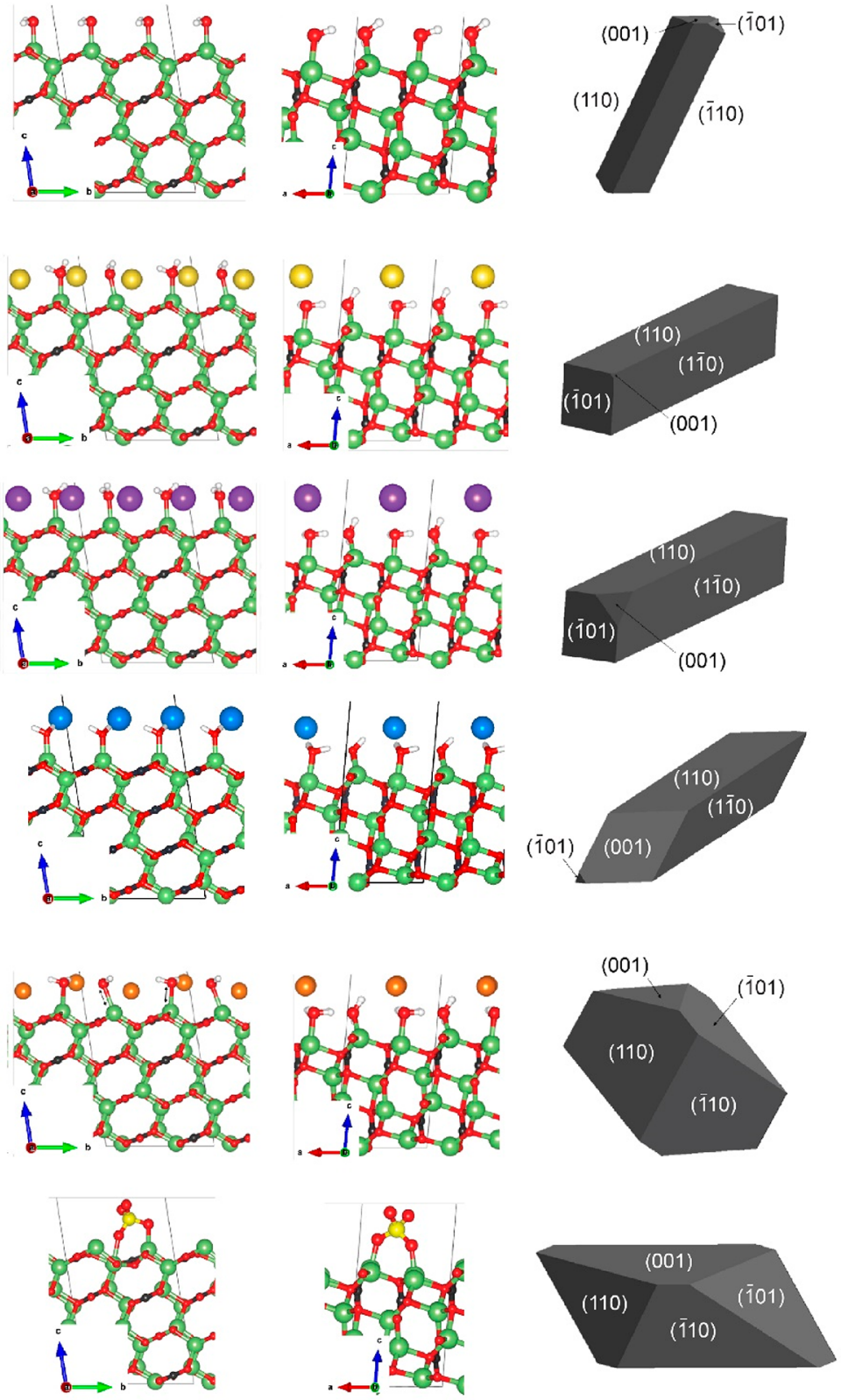

Figure 6. (a-f) Adsorption of different molecules and ions to the three dominant zabuyelite surfaces, (001), (101), and (110), and the resultant change in crystal morphology predicted based on the energies of the surfaces with the adsorbed molecules and ions.

to the concentration of background ions in solution, the chemistry of the ions present is also proposed to effect the hydration of ions differently. For example, the presence of specific ions in solution that do not directly interact with a growing or dissolving surface have also been found to influence the rate of material addition ${ }^{18}$ or removal, ${ }^{19,59}$ respectively, to/ from $\mathrm{Ca}$ - and $\mathrm{Mg}$-bearing carbonate mineral surfaces. This effect is linked to the hydration characteristics of both the background and solute ions and their effect on the bulk water structure. $^{60}$ The changes in water structure measured using the Raman spectrometer implies that the presence of $\mathrm{Li}^{+}$leads to more extensive changes than expected for the solution ionic strength compared to $\mathrm{Na}^{+}$salts. In addition, the enthalpy of hydration for the different cations tested in these experiments follows the order $\mathrm{Li}^{+}>\mathrm{Na}^{+}>\mathrm{K}^{+} .57$ Thus, given the elevated temperatures, which also disrupts $\mathrm{Li}^{+}$hydration, ${ }^{61}$ the presence of the different background ions is not expected to alter the ability of the mineral to form. This hypothesis is consistent with the similar nucleation times observed for the experiments conducted with the two different concentrations of the monovalent cation and previous observations that high $\mathrm{LiCl}$ concentrations produce the salting out effect for $\mathrm{Na}$ carbonate. $^{55}$

It is clear from the simulations that the presence of water at the surfaces of zabuyelite has a large effect on surface stability and, therefore, the crystal morphology. As the presence of different ions may also influence surface hydration and can facilitate ion dehydration during growth, ${ }^{62}$ the presence of 
different ions may also influence the crystal morphology. Both $\mathrm{Na}^{+}$and $\mathrm{K}^{+}$are unlikely to interact directly with the zabuyelite surfaces during growth based on the absence of changes in the surface groups of the zabuyelite observed with the ATR-IR and computational simulations of adsorption to hydrated zabuyelite surfaces. In addition, no large changes in morphology were predicted based on the presence of the two different ions, as was observed in the very similar aspect ratios for the crystals produced in the $1 \mathrm{M}$ solutions with $\mathrm{NaCl}$ or $\mathrm{KCl}$ (Table 2). This indicates that the presence of $\mathrm{Na}^{+}$or $\mathrm{K}^{+}$will not make a significant difference for the surface hydration, thus mineral growth. Similarly, $\mathrm{Cl}^{-}$ions were also found not to interact directly with the surface. However, a change in the morphology is observed when $1 \mathrm{M}$ of $\mathrm{NaCl}$ or $\mathrm{KCl}$ are present. For all three monatomic, monovalent ions, the most important faces on the elongated crystals are expected to be part of the $\{110\}$ form. Therefore, the changes in the width of the crystals observed in the experiments cannot be attributed to the presence of $\mathrm{Cl}^{-}$ versus $\mathrm{Br}^{-}$or the cations. Unlike the computational simulations and previous synthesis work where the faces with the largest areas were $\{110\}$ forms, ${ }^{37}$ the crystals formed in our experiments also express $\{010\}$ and, in the case of sulfate, $\{100\}$ forms. As the previous experiments were conducted at room temperature, as were the morphology simulations, it appears that additional crystal faces are stabilized during growth at $80{ }^{\circ} \mathrm{C}$. The increase in the width $\{010\}$ with increasing ionic strength, at the expense of the two additional faces at either side of the crystal ( width $_{\{110\}}$ ), implies that surface hydration disruption at the $\{010\}$ can facilitate growth.

4.3. Interaction between $\mathrm{Li}_{-}, \mathrm{Mg}-$, and $\mathrm{Ca}-\mathrm{Carbo-}$ nates. Formation of $\mathrm{Ca}$ and $\mathrm{Mg}$-carbonate phases was predicted by the PHREEQC calculations and observed in the experiments. Unlike $\mathrm{Na}^{+}$and $\mathrm{K}^{+}, \mathrm{Ca}^{2+}$, and $\mathrm{Mg}^{2+}$ effectively outcompete $\mathrm{Li}^{+}$for carbonate in solution. In the experiments with $0.033 \mathrm{M} \mathrm{CaCl}_{2}$ (0.1 M ionic strength), zabuyelite was observed to form in addition to calcite. Although the DFT simulations indicate that divalent ions could significantly alter the surface stabilities, a very similar, elongated morphology of the zabuyelite crystals was observed in the presence of $\mathrm{Ca}^{2+}$. There is some indication that the $\mathrm{Ca}^{2+}$ does interact with the crystal surface of zabuyelite as the $\{110\}$ surface width decreases on these crystals. This agrees with the simulations, which suggest that divalent, monatomic cations will make this surface less stable than observed with only water and monovalent, monatomic cations. In addition, the presence of $\mathrm{Ca}^{2+}$ appears to affect the crystallinity of zabuyelite as the FWHM of the carbonate symmetrical stretching Raman band increased. This could be related to a small amount of $\mathrm{Ca}^{2+}$ in the zabuyelite structure. A complete solid solution is not expected as the two carbonate minerals crystallize with different crystal structures. There was no clear shift in the center of the Raman band for the carbonate symmetrical stretch and no Ca was observed in the EDX spectra of the zabuyelite crystals. Therefore, the amount of $\mathrm{Ca}$ incorporated is expected to be less than $1 \mathrm{wt} \%$, the detection limit of the EDX. Up to 2 wt \% of $\mathrm{Li}$ has been reported in calcite, ${ }^{63}$ however, whether the reverse is possible is unclear as $\mathrm{Ca}^{2+}$ is considerably larger than the $\mathrm{Li}^{+}$ion $(0.99 \AA$ versus $0.68 \AA$, respectively $\left.{ }^{64}\right)$. Thus, it may be that there is insufficient space to incorporate larger ions in significant amounts without disrupting the crystal structure. This would fit with the experimental work with $\mathrm{K}^{+}$, another large cation $\left(1.33 \AA^{64}\right)$, for which no solid-solution compositions exist with $\mathrm{Li}_{2} \mathrm{CO}_{3}$ even at elevated temperatures. ${ }^{65}$

Calcite formation in the $0.033 \mathrm{M} \mathrm{CaCl}_{2}$ experiments $(0.1 \mathrm{M}$ ionic strength) is clearly influenced by the presence of $\mathrm{Li}^{+}$in solution. Two different morphologies of calcite were observed: a rhombohedral-like shape, and larger, platy crystals in some cases with 3 -fold rotational symmetry. The triangular shape at the center of the platy calcite crystal shown in Figure $3 \mathrm{~b}$ is very similar to what has been observed previously on $\{0001\}$ calcite surfaces stabilized by the adsorption of $\mathrm{Li}^{+} .{ }^{16,66}$ Viewing the calcite crystal along the [0001] direction would also explain the potential twin observed below the crystal with 3-fold rotation, as this is one of the twin planes of calcite. Similar to the zabuyelite precipitation mechanism proposed above, twins on the calcite (0001) surface are predicted to be the only type of twins that can occur via $2 \mathrm{D}$ heterogeneous nucleation. ${ }^{67}$ In contrast, in the Mg-bearing solutions, the Mg-carbonate dypingite dominates the precipitation of carbonate. However, zabuyelite growth in the presence of lower concentrations of $\mathrm{MgCl}_{2}$ to those used here produces shorter crystals. ${ }^{68}$ These crystals have a morphology that is close to that expected based on our simulations. Unlike calcite, dypingite crystals do not change their morphology when grown in different $\mathrm{Li}: \mathrm{Mg}$ ratios and show a morphology consistent with that of the dypingite crystals in the absence of $\mathrm{Li}^{+} .69$ This indicates that $\mathrm{Li}^{+}$does not directly influence the growth morphology of the dypingite. Interestingly, previous experiments at the synthesis temperatures used, more commonly produce less hydrated phases including nesquehonite $\left(\mathrm{MgCO}_{3} \cdot 3 \mathrm{H}_{2} \mathrm{O}\right)$ and hydromagnesite $\mathrm{Mg}_{5}\left(\mathrm{CO}_{3}\right)_{4} \cdot(\mathrm{OH})_{2} \cdot 4 \mathrm{H}_{2} \mathrm{O} .^{70,71}$ Given that $\mathrm{Li}^{+}$is proposed to aid the crystallization of other carbonates based on its strongly hydrated nature, these results imply that this effect is minimal on other strongly hydrated ions such as $\mathrm{Mg}^{2+}$. Alternatively, hydration is not the dominant barrier for anhydrous $\mathrm{Mg}$ carbonate formation as proposed in a recent paper by $\mathrm{Xu}$ et al. $^{72}$

4.4. Influence of Sulfate on Li Carbonate Growth. Lithium has a clear affinity for sulfate in the experiments, demonstrated by $\mathrm{SO}_{4}$ adsorption and the modification of the crystal morphology both in the computational simulations and experiments. Ion pair formation in solution is known to generate new bands in the Raman spectra of solutions which are present at slightly higher wavenumbers for oxyanions such as sulfate, ${ }^{23,24}$ as well as changes to the band position and symmetry for $\mathrm{Li}$ sulfate ion pairs in pure solutions at room temperature above concentrations of 0.2 molality. ${ }^{73}$ The strong hydration of $\mathrm{Li}^{+}$results in the ion pairs being solvent mediated rather than contact ion pairs at the temperature of our experiments. ${ }^{74}$ The increase in the band $\mathrm{FWHM}_{960}$ in the presence of $\mathrm{Li}$ indicates that Li-sulfate ion pairs were formed in our solutions in agreement with the PHREEQC simulations. Thus, $\mathrm{Li}^{+}$can effectively outcompete $\mathrm{Na}^{+}$to form ion pairs with sulfate in solution. The formation of ion pairs with sulfate is known to limit the nucleation of carbonate minerals. ${ }^{13}$ Therefore, in the experiments with Na-sulfate the decrease in $\mathrm{Li}^{+}$and $\mathrm{CO}_{3}{ }^{2-}$ ion activities due to the formation of ion pairs with sulfate and $\mathrm{Na}^{+}$, respectively, would lower the supersaturation of the system with respect to zabuyelite. Again, the formation of rosettes and hollow centers in many of the crystals implies that the nucleation is not limited sufficiently to alter the nucleation mechanism.

Evidence for sulfate incorporation during growth has been described for the Ca-carbonate calcite. ${ }^{75}$ Although thermody- 
namics predicts no solid solution between $\mathrm{Li}_{2} \mathrm{CO}_{3}$ and $\mathrm{Li}_{2} \mathrm{SO}_{4}{ }^{65}$ a metastable, mixed Li-carbonate and sulfate phase has been synthesized from melts at high temperatures. ${ }^{76}$ This phase was shown to increase the width of the Raman carbonate symmetrical stretching band at $1093 \mathrm{~cm}^{-1}$ in addition to the appearance of a new sulfate band. A similar increase in the FWHM of the carbonate band was observed in our sulfate experiments, however, no new band was observed in the vibrational spectroscopy data. The XRD analysis of zabuyelite synthesized in the experiments also showed no changes in the peak location or consistent increase of the FWHM. Therefore, if sulfate was incorporated into zabuyelite it is below the detection limit of the XRD and Raman spectrometer. The presence of sulfate during nucleation and growth can lead to the stabilization of different Ca-carbonate polymorphs. ${ }^{77}$ Thus, the increase in FWHM of the carbonate symmetrical stretching band indicates that a less crystalline material was produced, potentially due to sulfate disrupting the transformation of the precursor phase.

Sulfate has been observed to interact directly with growing ${ }^{13}$ and dissolving ${ }^{19}$ magnesite $\left(\mathrm{MgCO}_{3}\right)$ surfaces both at room temperature and $90{ }^{\circ} \mathrm{C}$. As $\mathrm{Mg}^{2+}$ also has a strong attraction for water molecules similar to $\mathrm{Li}^{+}$, it is likely that sulfate will also interact with zabuyelite surfaces. Indeed, the computational models predict that sulfate will bind directly to zabuyelite surfaces, unlike the other ions tested. Adsorption to the $\{110\}$ surfaces, however, increased the surface energy leading to a lower contribution of this surface in the equilibrium morphology (Figure 6f). The decrease in the stability of this surface through the adsorption of sulfate could be the reason for the small size of this surface on the crystals precipitated in the experiments. The shift of the sulfate symmetrical stretching band in the ATR-IR measurements is consistent with the adsorption of sulfate to mineral surfaces. ${ }^{47,78}$ Therefore, this implies that sulfate can directly adsorb to the zabuyelite surface as predicted by the computational simulations. However, it is not possible to identify adsorption to specific surfaces from the ATR-IR data. Similarly, the significant overlap of the sulfate band by the carbonate bands of zabuyelite prevent the determination of the dominant adsorption mode on the zabuyelite surfaces.

\section{CONCLUSIONS}

Both the experiments and computation simulations indicate that the ions with the most dominant effect on zabuyelite growth will be $\mathrm{Ca}^{2+}, \mathrm{Mg}^{2+}$, and $\mathrm{SO}_{4}{ }^{2-}$. Particularly, $\mathrm{Mg}^{2+}$ will limit Li-carbonate growth through the competitive precipitation of $\mathrm{Mg}$-carbonate phases, and thus removal of carbonate activity, which lowers the system supersaturation with respect to the Li-carbonate phase. In the industrial processes, this is alleviated by removing the $\mathrm{Mg}$ from the brine solution at the initial stages of Li extraction (see Meshram for a review ${ }^{9}$ ). However, this study demonstrates that even brines with low $\mathrm{Mg}$ may significantly limit the extraction of $\mathrm{Li}$. The morphological evidence of the calcite crystals from our experiments at $0.33 \mathrm{M} \mathrm{CaCl}_{2}$ indicates that the presence of significant amounts of $\mathrm{Li}$ can actually inhibit calcite formation from solution. Therefore, less Ca will need to be extracted to effectively precipitate $\mathrm{Li}$-carbonate. However, there is evidence that a small amount of $\mathrm{Ca}$ can be incorporated into the zabuyelite phase produced in the $0.033 \mathrm{M} \mathrm{CaCl}_{2}$ experiments. Thus, the zabuyelite produced may have a lower purity in the presence of $\mathrm{Ca}$. This may also occur when sulfate is present as there is also an increase in the FWHM of the carbonate symmetrical stretch in the Raman spectra of zabuyelite formed in these experiments.

Unlike the divalent ions, the monovalent ions examined here are expected only to form solvent-mediated interactions with the components of zabuyelite. Complexation with $\mathrm{Na}^{+}$may be important at low temperatures particularly for brines where $\mathrm{Na}^{+}$concentrations are typically higher than 5 wt $\%{ }^{12}$ However, our PHREEQC calculations indicate that the influence of monovalent cations such as $\mathrm{Na}^{+}$is lowered by increasing the temperature of the precipitating system. Chlorine is predicted to form less ion pairs with $\mathrm{Li}^{+}$in solution. Therefore, the presence of monovalent anions may be beneficial for altering the hydration of the growing surface and $\mathrm{Li}^{+}$in solution. For predictions of the effectiveness of $\mathrm{Li}$ extraction, thermodynamic data for the formation of the important Li-carbonate ion pairs and zabuyelite would be invaluable and should be targeted in future studies.

\section{ASSOCIATED CONTENT}

\section{S Supporting Information}

The Supporting Information is available free of charge on the ACS Publications website at DOI: 10.1021/acs.cgd.9b00782.

Summary of band positions found in the fluid cell Raman spectroscopy analysis (Table S1). Background for the DFT modeling including the calculated values of the lattice zabuyelite parameters and band gap (Table S2) as well as Figure S1 showing the density of states for the valence and conduction band of zabuyelite (PDF)

\section{AUTHOR INFORMATION}

\section{Corresponding Author}

*E-mail: h.e.king@uu.nl.

ORCID

Helen E. King: 0000-0002-1825-782X

Nelson Y. Dzade: 0000-0001-7733-9473

\section{Present Address}

\#(N.Y.D.) School of Chemistry, Main Building, Park Place, Cardiff, CF10 3AT, Wales.

\section{Notes}

The authors declare no competing financial interest.

The data used in this study is available online at the Pangaea Data Publisher (www.pangaea.de, DOI: 10.1594/PANGAEA.907049).

\section{ACKNOWLEDGMENTS}

This research was funded through the Department of Earth Sciences, Utrecht University, as part of the masters and bachelor's programs for A.S. and J.H., respectively. N.Y.D acknowledges the UK Engineering and Physical Sciences Research Council (EPSRC) for funding (Grant No. EP/ S001395/1). This work has also used the computational facilities of the Advanced Research Computing at Cardiff (ARCCA) Division, Cardiff University, and HPC Wales. The authors would like to thank Anita van Leeuwen-Tolboom and Herrick Schaink at Utrecht University for assistance with the XRD and ATR-IR analysis.

\section{REFERENCES}

(1) Medić, B.; Stojanović, M.; Stimec, B. V.; Divac, N.; Vujović, K. S.; Stojanović, R.; Colović, M.; Krstić, D.; Prostran, M. Lithium- 
Pharmacological and Toxicological Aspects: The Current State of the Art. Curr. Med. Chem. 2018, 25, DOI: 10.2174/ 0929867325666180904124733

(2) Goonan, T. G. Lithium Use in Batteries; US Geological Survey: Reston, VA, 2012; Circular 1371.

(3) Blomgren, G. E. The development and future of lithium ion batteries. J. Electrochem. Soc. 2017, 164, A5019-A5025.

(4) Gruber, P. W.; Medina, P. A.; Keoleian, G. A.; Kesler, S. E.; Everson, M. P.; Wallington, T. J. Global lithium availability: A constraint for electric vehicles? J. Ind. Ecol. 2011, 15, 760-775.

(5) Abe, Y. Rare metal series-current status of lithium resources JOGMEC Mineral Resources Report, 2010.

(6) Chitrakar, R.; Makita, Y.; Ooi, K.; Sonoda, A. Selective uptake of lithium ion from brine by $\mathrm{H}_{1.33} \mathrm{Mn}_{1.67} \mathrm{O}_{4}$ and $\mathrm{H}_{1.6} \mathrm{Mn}_{1.6} \mathrm{O}_{4}$. Chem. Lett. 2012, 41, 1647-1649.

(7) Chitrakar, R.; Makita, Y.; Ooi, K.; Sonoda, A. Lithium recover from salt lake brine by $\mathrm{H}_{2} \mathrm{TiO}_{3}$. Dalton Transactions 2014, 43, 89338939.

(8) Liu, X.; Chen, X.; He, L.; Zhao, Z. Study on extraction of lithium from salt lake brine by membrane electrolysis. Desalination 2015, 376, $35-40$.

(9) Meshram, P.; Pandey, B. D.; Mankhand, T. R. Extraction of lithium from primary and secondary sources by pretreatment, leaching and separation: A comprehensive review. Hydrometallurgy 2014, 150, 192-208.

(10) Kondás, J.; Jandová, J.; Nemeckova, M. Processing of spent Li/ $\mathrm{MnO}_{2}$ batteries to obtain $\mathrm{Li}_{2} \mathrm{CO}_{3}$. Hydrometallurgy 2006, 84, 247249.

(11) Watamura, H.; Marukawa, H.; Hirasawa, I. Polyelectrolyte effects on the crystallization phenomena of the lithium carbonate. $J$. Cryst. Growth 2013, 373, 111-117.

(12) An, J. W.; Kang, D. J.; Tran, K. T.; Kim, M. J.; Lim, T.; Tran, T. Recovery of lithium from Uyuni salar brine. Hydrometallurgy 2012, $117,64-70$.

(13) King, H. E.; Satoh, H.; Tsukamoto, K.; Putnis, A. Nanoscale observations of magnesite growth in chloride- and sulfate-rich solutions. Environ. Sci. Technol. 2013, 47, 8684-8691.

(14) Jiang, G.; Fu, H.; Savino, K.; Qian, J.; Wu, Z.; Guan, B. Nonlattice cation- $\mathrm{SO}_{4}$-ion pairs in calcium sulfate hemihydrate nucleation. Cryst. Growth Des. 2013, 13, 5128-5134.

(15) Titiloye, J. O.; Parker, S. C.; Osguthorpe, D. J.; Mann, S. Predicting the influence of growth additives on the morphology of ionic crystals. J. Chem. Soc., Chem. Commun. 1991, 1494-1496.

(16) Rajam, S.; Mann, S. Selective stabilization of the (001) face of calcite in the presence of lithium. J. Chem. Soc., Chem. Commun. 1990, 1789-1791.

(17) Pastero, L.; Costa, E.; Bruno, M.; Rubbo, M.; Sgualdino, G.; Aquilano, D. Morphology of calcite $\left(\mathrm{CaCO}_{3}\right)$ crystals growing from aqueous solutions in the presence of the Li ions. Surface behavior of the $\{0001\}$ form. Cryst. Growth Des. 2004, 4, 485-490.

(18) Ruiz-Agudo, E.; Putnis, C. V.; Wang, L.; Putnis, A. Specific effects of background electrolytes on the kinetics of step propagation during calcite growth. Geochim. Cosmochim. Acta 2011, 75, 38033814.

(19) King, H. E.; Putnis, C. V. Direct observations of the influence of solution composition on magnesite dissolution. Geochim. Cosmochim. Acta 2013, 109, 113-126.

(20) Taborga, P.; Brito, I.; Graber, T. A. Effect of additives on size and shape of lithium carbonate crystals. J. Cryst. Growth 2017, 460, 5-12.

(21) Nie, Z.; Bu, L. Z.; Zheng, M. P.; Zhang, Y. S. Phase chemistry study of the Zabuye Salt Lake brine: isothermal evaporation at 15 and $25{ }^{\circ}$ C. Acta Geol. Sin. 2010, 84, 1533-1538.

(22) Geisler, T.; Perdikouri, C.; Kasioptas, A.; Dietzel, M. Real-time monitoring of the overall exchange of oxygen isotopes between aqueous $\mathrm{CO}_{3}{ }^{2-}$ and $\mathrm{H}_{2} \mathrm{O}$ by Raman spectroscopy. Geochim. Cosmochim. Acta 2012, 90, 1-11.
(23) Rudolph, W. W.; Irmer, G.; Hefter, G. T. Raman spectroscopic investigation of speciation in $\mathrm{MgSO}_{4}(\mathrm{aq})$. Phys. Chem. Chem. Phys. 2003, 5, 5253-5261.

(24) Wang, X.; Wang, X.; Chou, I.; Hu, W.; Wan, Y.; Li, Z. Properties of lithium under hydrothermal conditions revealed by in situ Raman spectroscopic characterization of $\mathrm{Li}_{2} \mathrm{O}-\mathrm{SO}_{3}-\mathrm{H}_{2} \mathrm{O}\left(\mathrm{D}_{2} \mathrm{O}\right)$ systems at temperatures up to $420{ }^{\circ} \mathrm{C}$. Chem. Geol. 2017, 451, 104115.

(25) Wojdyr, M. Fityk: a general-purpose peak fitting program. J. Appl. Crystallogr. 2010, 43, 1126-1128.

(26) Um, J.; McFarquhar, G. M.; Hong, Y. P.; Lee, S. S.; Jung, C. H.; Lawson, R. P.; Mo, Q. Dimensions and aspect ratios of natural ice crystals. Atmos. Chem. Phys. 2015, 15, 3933-3956.

(27) Parkhurst, D. L.; Appelo, C. Description of input and examples for PHREEQC version 3: a computer program for speciation, batchreaction, one-dimensional transport, and inverse geochemical calculations. U.S. Geological Survey Techniques and Methods Report, 2013.

(28) Idemoto, Y.; Richardson, J. W., Jr; Koura, N.; Kohara, S.; Loong, C. Crystal structure of $\left(\mathrm{Li}_{\mathrm{x}} \mathrm{K}_{1-\mathrm{x}}\right)_{2} \mathrm{CO}_{3}(\mathrm{x}=0,0.43,0.5,0.62,1)$ by neutron powder diffraction analysis. J. Phys. Chem. Solids 1998, 59, 363-376.

(29) Monkhorst, H. J.; Pack, J. D. Special points for Brillouin-zone integrations. Phys. Rev. B 1976, 13, 5188.

(30) Watson, G. W.; Kelsey, E. T.; de Leeuw, N. H.; Harris, D. J.; Parker, S. C. Atomistic simulation of dislocations, surfaces and interfaces in MgO. J. Chem. Soc., Faraday Trans. 1996, 92, 433-438.

(31) Tasker, P. W. The stability of ionic crystal surfaces. J. Phys. C: Solid State Phys. 1979, 12, 4977.

(32) Makov, G.; Payne, M. C. Periodic boundary conditions in ab initio calculations. Phys. Rev. B: Condens. Matter Mater. Phys. 1995, 51, 4014.

(33) Wulff, G. On the question of speed of growth and dissolution of crystal surfaces. Z. Kristallogr. 1901, 34, 449.

(34) Rudolph, W. W.; Irmer, G.; Königsberger, E. Speciation studies in aqueous $\mathrm{HCO}_{3}{ }^{-}-\mathrm{CO}_{3}{ }^{2-}$ solutions. A combined Raman spectroscopic and thermodynamic study. Dalton T 2008, 900-908.

(35) Li, R.; Jiang, Z.; Chen, F.; Yang, H.; Guan, Y. Hydrogen bonded structure of water and aqueous solutions of sodium halides: a Raman spectroscopic study. J. Mol. Struct. 2004, 707, 83-88.

(36) Terpstra, P.; Combes, D.; Zwick, A. Effect of salts on dynamics of water: A Raman spectroscopy study. J. Chem. Phys. 1990, 92, 6570.

(37) Pastero, L.; Massaro, F. R.; Aquilano, D. Experimental and theoretical morphology of single and twinned crystals of $\mathrm{Li}_{2} \mathrm{CO}_{3}$ (zabuyelite). Cryst. Growth Des. 2007, 7, 2749-2755.

(38) Anderson, A. J.; Clark, A. H.; Gray, S. The occurrence and origin of zabuyelite $\left(\mathrm{Li}_{2} \mathrm{CO}_{3}\right)$ in spodumene-hosted fluid inclusions: implications for the internal evolution of rare-element granitic pegmatites. Can. Mineral. 2001, 39, 1513-1527.

(39) Bhagavantam, S. Effect of crystal orientation on the Raman spectrum of calcite. Proc. - Indian Acad. Sci., Sect. A 1940, 11, 62-71.

(40) Nasdala, L.; Irmer, G.; Wolf, D. The degree of metamictization in zircons: a Raman spectroscopic study. Eur. J. Mineral. 1995, 7, $471-478$.

(41) Andersen, F. A.; Brecevic, L. Infrared spectra of amorphous and crystalline calcium carbonate. Acta Chem. Scand. 1991, 45, 10181024.

(42) Frost, R. L.; Bahfenne, S.; Graham, J. Raman spectroscopic study of the magnesium-carbonate minerals-artinite and dypingite. $J$. Raman Spectrosc. 2009, 40, 855-860.

(43) de Leeuw, N. H.; Parker, S. C. Surface structure and morphology of calcium carbonate polymorphs calcite, aragonite, and vaterite: an atomistic approach. J. Phys. Chem. B 1998, 102, 29142922.

(44) Acelas, N. Y.; Mejia, S. M.; Mondragón, F.; Flórez, E. Density functional theory characterization of phosphate and sulfate adsorption on Fe-(hydr)oxide: Reactivity, pH effect estimation of Gibbs free 
energies, and topological analysis of hydrogen bonds. Comput. Theor. Chem. 2013, 1005, 16-24.

(45) Paul, K. W.; Kubicki, J. D.; Sparks, D. L. Quantum chemical calculations of sulfate adsorption at the Al- and Fe-(hydr)oxide- $\mathrm{H}_{2} \mathrm{O}$ interface-Estimation of Gibbs free energies. Environ. Sci. Technol. 2006, 40, 7717-7724.

(46) Alia, J. M.; de Mera, Y. D.; Edwards, H.; Martín, P. G.; Andres, S. L. FT-Raman and infrared spectroscopic study of aragonitestrontianite $\left(\mathrm{Ca}_{\mathrm{x}} \mathrm{Sr}_{1-\mathrm{x}} \mathrm{CO}_{3}\right)$ solid solution. Spectrochim. Acta, Part A 1997, 53, 2347-2362.

(47) Müller, K.; Lefevre, G. Vibrational characteristics of outersphere surface complexes: example of sulfate ions adsorbed onto metal (hydr)oxides. Langmuir 2011, 27, 6830-6835.

(48) Wang, S.; Guo, Y.; Yang, J.; Deng, T. Solid-liquid phase equilibria in the ternary system $\left(\mathrm{LiBO}_{2+} \mathrm{Li}_{2} \mathrm{CO}_{3+} \mathrm{H}_{2} \mathrm{O}\right)$ at 288.15 and 298.15 K. Russ. J. Phys. Chem. A 2015, 89, 2190-2196.

(49) Eitel, W.; Skaliks, W. Concerning a few double carbonates of alkalis and alkaline earths. Z. Anorg. Allg. Chem. 1929, 183, 263-286.

(50) Rieger, J.; Frechen, T.; Cox, G.; Heckmann, W.; Schmidt, C.; Thieme, J. Precursor structures in the crystallization/precipitation processes of $\mathrm{CaCO}_{3}$ and control particle formation by polyelectrolytes. Faraday Discuss. 2007, 136, 265-277.

(51) Shi, S.; Su, Z.; Wei, H.; Chen, X. Fabrication of aragonite rosette superstructure through the weak interaction between nonionic polymers and $\mathrm{Ca}^{2+}$. J. Appl. Polym. Sci. 2010, 117, 3308-3314.

(52) Bailey, M.; Hallett, J. Growth rates and habits of ice crystals between -20 and $-70{ }^{\circ} \mathrm{C}$. J. Atmos. Sci. 2004, 61, 514-544.

(53) Yu, J. G.; Guo, H.; Davis, S. A.; Mann, S. Fabrication of hollow inorganic microspheres by chemically induced self-transformation. Adv. Funct. Mater. 2006, 16, 2035-2041.

(54) Moore, R. C.; Mesmer, R. E.; Simonson, J. M. Solubility of potassium carbonate in water between 384 and $529 \mathrm{~K}$ measured using the synthetic method. J. Chem. Eng. Data 1997, 42, 1078-1081.

(55) Yu, X.; Zeng, Y.; Mu, P.; Yin, Q.; Tan, Q. Thermodynamics phase equilibria for systems containing lithium, sodium, chloride, and carbonate in aqueous solution at 273.15 K. J. Chem. Eng. Data 2013, $58,2799-2804$.

(56) Marcus, Y. Effect of ions on the structure of water: Structure making and breaking. Chem. Rev. 2009, 109, 1346-1370.

(57) Ichieda, N.; Kasuno, M.; Banu, K.; Kihara, S.; Nakamatsu, H. Evaluation of hydration enthalpies of monatomic cations by considering both long-range and short-range interactions. J. Phys. Chem. A 2003, 107, 7597-7603.

(58) Coto, B.; Martos, C.; Peña, J. L.; Rodríguez, R.; Pastor, G. Effects of the solubility of $\mathrm{CaCO}_{3}$ : Experimental study and model description. Fluid Phase Equilib. 2012, 324, 1-7.

(59) Ruiz-Agudo, E.; Urosevic, M.; Putnis, C. V.; RodríguezNavarro, C.; Cardell, C.; Putnis, A. Ion-specific effects on the kinetics of mineral dissolution. Chem. Geol. 2011, 281, 364-371.

(60) Zangi, R. Can salting-in/salting-out ions be classified as chaotropes/kosmotropes? J. Phys. Chem. B 2010, 114, 643-650.

(61) Egorov, A. V.; Komolkin, A. V.; Chizhik, V. I.; Yushmanov, P. V.; Lyubartsev, A. P.; Laaksonen, A. Temperature and concentration effects on $\mathrm{Li}^{+}$-ion hydration. A molecular dynamics simulation study. J. Phys. Chem. B 2003, 107, 3234-3242.

(62) Piana, S.; Jones, F.; Gale, J. D. Assisted desolvation as a key kinetic step for crystal growth. J. Am. Chem. Soc. 2006, 128, 1356813574.

(63) Ogino, T.; Suzuki, T.; Sawada, K. The rate and mechanism of polymorphic transformation of calcium carbonate in water. J. Cryst. Growth 1990, 100, 159-167.

(64) Ahrens, L. H. The use of ionization potentials Part 1. Ionic radii of the elements. Geochim. Cosmochim. Acta 1952, 2, 155-169.

(65) Pelton, A. D.; Bale, C. W.; Lin, P. L. Calculation of phase diagrams and thermodynamic properties of 14 additive and reciprocal ternary systems containing $\mathrm{Li}_{2} \mathrm{CO}_{3}, \mathrm{Na}_{2} \mathrm{CO}_{3}, \mathrm{~K}_{2} \mathrm{CO}_{3}, \mathrm{Li}_{2} \mathrm{SO}_{4}, \mathrm{Li}_{2} \mathrm{SO}_{4}$,$\mathrm{K}_{2} \mathrm{SO}_{4}, \mathrm{LiOH}, \mathrm{NaOH}$, and KOH. Can. J. Chem. 1984, 62, 457-474.
(66) Pastero, L.; Aquilano, D. $\mathrm{CaCO}_{3}$ (calcite)/ $\mathrm{Li}_{2} \mathrm{CO}_{3}$ (zabuyelite) anomalous mixed crystals. Sector zoning and growth mechanisms. Cryst. Growth Des. 2008, 8, 3451-3460.

(67) Bruno, M.; Massaro, F. R.; Rubbo, M.; Prencipe, M.; Aquilano, D. Ab initio quantum-mechanical modeling of the (001), (101) and (110) surfaces of zabuyelite $\left(\mathrm{Li}_{2} \mathrm{CO}_{3}\right)$. Surf. Sci. 2007, 601, 30123019.

(68) Mikami, T.; Koseki, T. Reactive crystallization of lithium carbonate in the presence of magnesium impurity. J. Chem. Eng. Jpn. 2017, 50, 309-314.

(69) Canterford, J. H.; Tsambourakis, G.; Lambert, B. Some observations on the properties of dypingite, $\mathrm{Mg}_{5}\left(\mathrm{CO}_{3}\right)_{4}(\mathrm{OH})_{2} \cdot 5 \mathrm{H}_{2} \mathrm{O}$, and related minerals. Mineral. Mag. 1984, 48, 437-442.

(70) King, H. E.; Plümper, O.; Putnis, A. Effect of secondary phase formation on the carbonation of olivine. Environ. Sci. Technol. 2010, 44, 6503-6509.

(71) Hänchen, M.; Prigiobbe, V.; Baciocchi, R.; Mazzotti, M. Precipitation in the Mg-carbonate system-effects of temperature and $\mathrm{CO}_{2}$ pressure. Chem. Eng. Sci. 2008, 63, 1012-1028.

(72) Xu, J.; Yan, C.; Zhang, F.; Konishi, H.; Xu, H.; Teng, H. H. Testing the cation-hydration effect on the crystallization of Ca-Mg$\mathrm{CO}_{3}$ systems. Proc. Natl. Acad. Sci. U. S. A. 2013, 110, 17750-17755.

(73) Tomišić, V.; Simeon, V. Raman spectra of aqueous solutions of strong electrolytes: evolving-factor analysis. Phys. Chem. Chem. Phys. 2000, 2, 1943-1949.

(74) Wachter, W.; Fernandez, Š; Buchner, R.; Hefter, G. Ion association and hydration in aqueous solutions of $\mathrm{LiCl}$ and $\mathrm{Li}_{2} \mathrm{SO}_{4}$ by dielectric spectroscopy. J. Phys. Chem. B 2007, 111, 9010-9017.

(75) Vavouraki, A. I.; Putnis, C. V.; Putnis, A.; Koutsoukos, P. G. An atomic force microscopy study of the growth of calcite in the presence of sodium sulfate. Chem. Geol. 2008, 253, 243-251.

(76) Aliev, A. R.; Akhmedov, I. R.; Kakagasanov, M. G.; Aliev, Z. A.; Gafurov, M. M.; Amirov, A. M. Molecular relaxation in $\mathrm{LiNO}_{3}-\mathrm{LiClO}_{4}$ and $\mathrm{Li}_{2} \mathrm{CO}_{3}-\mathrm{Li}_{2} \mathrm{SO}_{4}$ solid binary systems. Russ. Phys. J. 2018, 61, 292298.

(77) Cuesta Mayorga, I.; Astilleros, J. M.; Fernández-Díaz, L. Precipitation of $\mathrm{CaCO}_{3}$ polymorphs from aqueous solutions: The role of $\mathrm{pH}$ and sulphate groups. Minerals 2019, 9, 178.

(78) Fukushi, K.; Aoyama, K.; Yang, C.; Kitadai, N.; Nakashima, S. Surface complexation modeling for sulfate adsorption on ferrihydrite consistent with in situ infrared spectroscopic observations. Appl. Geochem. 2013, 36, 92-103. 